Guideline

\title{
Executive Summary: HRS/EHRA/APHRS Expert Consensus Statement on the Diagnosis and Management of Patients with Inherited Primary Arrhythmia Syndromes 败, 访抎
}

Silvia G. Priori, MD, PhD, HRS Chairperson ${ }^{1, *}$, Arthur A. Wilde, MD, PhD, EHRA Chairperson ${ }^{2}$, Minoru Horie, MD, PhD, APHRS Chairperson ${ }^{3}$, Yongkeun Cho, MD, PhD, APHRS Chairperson ${ }^{4}$, Elijah R. Behr, MA, MBBS, MD, FRCP ${ }^{5}$, Charles Berul, MD, FHRS, CCDS ${ }^{6}$, Nico Blom, MD, PhD ${ }^{7, *}$, Josep Brugada, $\mathrm{MD}, \mathrm{PhD}^{8}$, Chern-En Chiang, $\mathrm{MD}, \mathrm{PhD}^{9}$, Heikki Huikuri, $\mathrm{MD}^{10}$, Prince Kannankeril, MD ${ }^{11,}$, Andrew Krahn, MD, FHRS ${ }^{12}$, Antoine Leenhardt, MD ${ }^{13}$, Arthur Moss, MD ${ }^{14}$, Peter J. Schwartz, MD ${ }^{15}$, Wataru Shimizu, MD, PhD ${ }^{16}$, Gordon Tomaselli, MD, FHRS ${ }^{17, \dagger}$, Cynthia Tracy, MD ${ }^{18, \%}$

\footnotetext{
${ }^{1}$ Maugeri Foundation IRCCS, Pavia, Italy, Department of Molecular Medicine, University of Pavia, Pavia, Italy, and New York University, New York, New York

${ }^{2}$ Department of Cardiology, Academic Medical Centre, Amsterdam, Netherlands, Princess Al-Jawhara Al-Brahim Centre of Excellence in Research of

Hereditary Disorders, Jeddah, Kingdom of Saudi Arabia

${ }^{3}$ Shiga University of Medical Sciences, Otsu, Japan

${ }^{4}$ Kyungpook National University Hospital, Daegu, South Korea

${ }^{5}$ St. Georges University of London, United Kingdom

${ }^{6}$ Children's National Medical Center, Washington, DC, United States

${ }^{7}$ Academical Medical Center, Amsterdam, Leiden University Medical Center, Leiden, Netherlands

${ }^{8}$ University of Barcelona, Barcelona, Spain

${ }^{9}$ Taipei Veteran's General Hospital, Taipei, Taiwan

${ }^{10}$ Oulu University Central Hospital, Oulu, Finland

${ }^{11}$ Vanderbilt Children's Hospital, Nashville, Tennessee, United States

${ }^{12}$ Sauder Family and Heart and Stroke Foundation University of British Columbia, British Columbia, Canada

${ }^{13}$ Bichat University Hospital, Paris, France

${ }^{14}$ University of Rochester Medical Center, Rochester, New York, United States

${ }^{15}$ Department of Molecular Medicine, University of Pavia, Pavia, Italy

${ }^{16}$ Nippon Medical School, Tokyo, Japan

${ }^{17}$ Johns Hopkins University, Baltimore, Maryland, United States

${ }^{18}$ George Washington University Medical Center, Washington, DC, United States
}

\section{Introduction}

This international consensus statement is the collaborative effort of three medical societies representing electrophysiology in North

Document endorsed by HRS, EHRA, and APHRS in May 2013 and by ACCF, AHA, PACES, and AEPC in June 2013.

Developed in partnership with the Heart Rhythm Society (HRS), the European Heart Rhythm Association (EHRA), a registered branch of the European Society of Cardiology (ESC), and the Asia Pacific Heart Rhythm Society (APHRS) and in collaboration with the American College of Cardiology Foundation (ACCF), the American Heart Association (AHA), the Pediatric and Congenital Electrophysiology Society (PACES), and the Association for European Pediatric and Congenital Cardiology (AEPC).

* Address correspondence: Sheila Tynes

E-mail address:

STynes@hrsonline.org (S.G. Priori).

Representative for American College of Cardiology.

Representative for American Heart Association.

Representative for Pediatric and Congenital Electrophysiology Society.

Representative for Association for European Pediatric and Congenital Cardiology.
America, Europe, and Asian-Pacific area: the Heart Rhythm Society (HRS), the European Heart Rhythm Association (EHRA), and the Asia Pacific Heart Rhythm Society. The objective of the consensus document is to provide clinical guidance for diagnosis, risk stratification, and management of patients affected by inherited primary arrhythmia syndromes. It summarizes the opinion of the international writing group members based on their own experience and on a general review of the literature with respect to the clinical data on patients affected by channelopathies.

This document does not address the indications of genetic testing in patients affected by inherited arrhythmias and their family members. Diagnostic, prognostic, and therapeutic implications of the results of genetic testing are also not included in this document because this topic has been covered by a recent publication ${ }^{1}$ coauthored by some of the contributors of this consensus document, and it remains the reference text on this topic. Guidance for the evaluation of patients with idiopathic ventricular fibrillation, sudden arrhythmic death syndrome, and sudden unexplained death in infancy, which includes genetic 
testing, are provided as these topics were not covered in the previous consensus statement.

Developing guidance for genetic diseases requires adaptation of the methodology adopted to prepare guidelines for clinical practice. Documents produced by other medical societies have acknowledged the need to define the criteria used to rank the strength of recommendation for genetic diseases. ${ }^{2}$

The most obvious difference encountered for inherited diseases is that randomized and/or blinded studies do not exist in this field. Therefore, most of the available data derive from registries that have followed patients and recorded outcome information. As a consequence, all consensus recommendations are level of evidence $C$ (i.e., based on experts' opinions).

The consensus recommendations in this document use the commonly used Class I, IIa, IIb, and III classification and the corresponding language: "is recommended" for Class I consensus recommendation; "can be useful" for a Class Ila consensus recommendation; "may be considered" to signify a Class IIb consensus recommendation; "should not" or "is not recommended" for a Class III consensus recommendation (failure to provide any additional benefit and may be harmful).

\section{Definitions of special terms used in the document}

The terms used in the consensus document are defined as follows:

- Syncope: In the context of inherited arrhythmogenic disorders, the occurrence of "syncope" is an important indicator of arrhythmic risk. Although there is no definition to differentiate a syncopal episode caused by ventricular arrhythmias from an otherwise unexplained syncope, in the context of this document, the term "syncope" implies the exclusion of events that are likely due to vasovagal events such as those occurring during abrupt postural changes, exposure to heat and dehydration, and emotional reactions to events such as blood drawing. We refer to the guidelines of ESC and AHA/ACCF for the differential diagnoses of syncope. ${ }^{3,4}$

- Symptomatic individuals: The term "symptomatic" refers to individuals who have experienced ventricular arrhythmias (usually ventricular tachycardia or resuscitated ventricular fibrillation) or syncopal episodes (see definition above). The presence of symptoms is, in some of the channelopathies, an independent predictor of cardiac arrest at follow-up.

- Arrhythmic events: The term refers to the occurrence of symptomatic or asymptomatic sustained or nonsustained spontaneous ventricular tachycardia or unexplained syncope/ resuscitated cardiac arrest.

- Concealed mutation-positive patients: This term is used to refer to individuals without clinical symptoms or phenotype of a channelopathy who carry the genetic defect present in clinically affected members of the family.

\section{Methodological aspects and instructions for the consultation of the document}

When considering the guidance from this document, it is important to remember that there are no absolutes governing many clinical situations. The final judgment regarding care of a particular patient must be made by the health-care provider and the patient in light of all relevant circumstances. Recommendations are based on the consensus of the writing group following the Heart Rhythm Society's established consensus process. It is recognized that consensus does not mean unanimous agreement among all writing group members. We identified the aspects of patients' care for which a true consensus could be found. Surveys of the entire writing group were used. The authors received an agreement that was greater than or equal to $84 \%$ on all recommendations; most recommendations received agreement of $94 \%$ or higher.

This statement is directed to all health-care professionals who are involved in the management of (1) individuals who survived a cardiac arrest at a young age (usually defined as $<40$ years) in the absence of a clinical diagnosis of cardiac disease, despite extensive clinical assessment; (2) family members of individuals who died suddenly at young age with a negative autopsy; (3) in patients and family members in whom the diagnosis of a channelopathy is clinically possible, likely, or established; and (4) young patients with unexplained syncope.

All members of this document writing group provided disclosure statements of all relationships that might present real or perceived conflicts of interest. Disclosures for all members of the writing group are published in Appendix A.

\section{Long QT Syndrome (LQTS)}

Expert Consensus Recommendations on LQTS Diagnosis

1. LQTS is diagnosed:

a. In the presence of an LQTS risk score $\geq 3.5$ in the absence of a secondary cause for QT prolongation and/or

b. In the presence of an unequivocally pathogenic mutation in one of the LQTS genes or

c. In the presence of a corrected QT interval for heart rate using Bazett's formula (QTc) $\geq 500 \mathrm{~ms}$ in repeated 12lead electrocardiogram (ECG) and in the absence of a secondary cause for QT prolongation.

2. LQTS can be diagnosed in the presence of a QTc between 480 and $499 \mathrm{~ms}$ in repeated 12-lead ECGs in a patient with unexplained syncope in the absence of a secondary cause for QT prolongation and in the absence of a pathogenic mutation.

Expert Consensus Recommendations on LQTS Therapeutic Interventions

Class I 1. The following lifestyle changes are recommended in all patients with a diagnosis of LQTS:

a. Avoidance of QT-prolonging drugs (www. qtdrugs.org)

b. Identification and correction of electrolyte abnormalities that may occur during diarrhea, vomiting, metabolic conditions, or imbalanced diets for weight loss.

2. Beta-blockers are recommended in patients with a diagnosis of LQTS who are:

a. Asymptomatic with QTc $>470 \mathrm{~ms}$ and/or

b. Symptomatic for syncope or documented ventricular tachycardia/ventricular fibrillation (VT/VF).

3. Left cardiac sympathetic denervation (LCSD) is recommended in high-risk patients with a diagnosis of LQTS in whom:

a. Implantable cardioverter-defibrillator (ICD) therapy is contraindicated or refused and/or

b. Beta-blockers are either not effective in preventing syncope/arrhythmias, not tolerated, not accepted or contraindicated. 
4. ICD implantation is recommended in patients with a diagnosis of LQTS who are survivors of a cardiac arrest.

5. All LQTS patients who wish to engage in competitive sports should be referred to a clinical expert for the evaluation of risk.

Class 6. Beta-blockers can be useful in patients with a diagnosis of LQTS who are asymptomatic with QTC $\leq 470 \mathrm{~ms}$.

7. ICD implantation can be useful in patients with a diagnosis of LQTS who experience recurrent syncopal events while on beta-blocker therapy.

8. LCSD can be useful in patients with a diagnosis of LQTS who experience breakthrough events while on therapy with beta-blockers/ICD.

9. Sodium channel blockers can be useful, as add-on therapy, for LQT3 patients with a QTc > $500 \mathrm{~ms}$ who shorten their QTc by $>40 \mathrm{~ms}$ following an acute oral drug test with one of these compounds.

Class 10. Except under special circumstances, ICD

III implantation is not indicated in asymptomatic LQTS patients who have not been tried on betablocker therapy.

\section{Epidemiology}

Patients affected by the LQTS have been identified all over the world and in all ethnic groups. A possible exception is represented by a paucity of cases identified among black Africans and among African-Americans. Among Caucasians, the prevalence of LQTS has been 1:2000 apparently healthy live births. ${ }^{5}$

\section{Clinical manifestations}

The clinical manifestations of LQTS fall under two main categories: the arrhythmic events and the ECG aspects.

The arrhythmic events are due to runs of torsades de pointes VT, which, according to its duration, produces syncope and-when it deteriorates into VF-cardiac arrest or sudden death.

In ECG alterations, prolongation of the QT interval is the hallmark of LQTS but it is not always present. Ventricular repolarization is not only prolonged but often presents bizarre morphologic alterations, some of which tend to be gene-specific. ${ }^{6}$

\section{Diagnosis}

The diagnosis of LQTS is mainly based on the measurement of the QTc. When using a prolonged QTc to diagnose LQTS, one must exclude secondary causes of QTc prolongation that can occur with drugs, acquired cardiac conditions, electrolyte imbalance, and unbalanced diets. A scoring system has been established, which takes into account the age of the patient, medical and family history, symptoms, and QTc and provides a probability of the diagnosis of LQTS. ${ }^{7,8}$

Approximately $20 \%-25 \%$ of the patients with LQTS confirmed by the presence of an LQTS gene mutation may have a normal range QTc. ${ }^{9,10}$

\section{Risk stratification}

Individuals at the extremes of the curve, those at very high or at very low risk, are easy to identify. For the larger group, in the gray area, risk stratification is difficult and can be fraught with errors in either direction. The Jervell and Lange-Nielsen syndrome $^{11}$ and the extremely rare Timothy syndrome (LQT8) ${ }^{12}$ are highly malignant, manifest with major arrhythmic events, and respond poorly to therapies. Within the most common genetic groups, specific locations, types of mutations, and degree of mutation dysfunction are associated with different risks.

High risk is present whenever QTc $>500 \mathrm{~ms}^{9,13}$ and becomes extremely high whenever QTc $>600 \mathrm{~ms}$. Patients with two unequivocally pathogenic variants and a QTc $>500 \mathrm{~ms}$ are also at high risk. The presence of overt T-wave alternans is a direct sign of electrical instability and calls for preventive measures. Patients who have syncope or cardiac arrest before age 7 have a higher probability of recurrence of arrhythmic events while on betablockers. ${ }^{14}$ Patients who have syncope or cardiac arrest in the first year of life are at high risk for lethal events and may not be fully protected by the traditional therapies. ${ }^{15,16}$ Patients who suffer arrhythmic events despite being on full medical therapy are at higher risk.

\section{Management}

Lifestyle modifications such as avoidance of strenuous exercise and avoidance of drugs that prolong QT interval in all LQTS patients should be routine. Participation of LQTS patients in competitive sports is still a matter of debate among the experts. Specific therapies available for patients with LQTS and indications for their use are described below.

\section{Beta-blockers}

Beta-blockers are clinically indicated in LQTS, including those with a genetic diagnosis and normal QTc, unless there is a contraindication such as active asthma. ${ }^{14,15}$ Although studies are not available to define the most effective dosage, full dosing for age and weight, if tolerated, is recommended. Abrupt discontinuation of beta-blockers should be avoided as this may increase the risk of exacerbation.

\section{ICD (Figure 1)}

ICD therapy is indicated in LQTS patients who are resuscitated from cardiac arrest. ${ }^{17}$ ICD is often favored in patients with LQTSrelated syncope who also receive beta-blockers. ${ }^{18}$ Prophylactic ICD therapy should be considered in very high risk patients. ICD therapy has lifetime implications, complications are not infrequent, especially in the younger age group, and risk/benefit considerations should be carefully considered before initiating this invasive therapy. ${ }^{19,20}$

We suggest that ICD therapy not be used as first-line therapy in an asymptomatic LQTS patient; beta-blockers remain the first-line therapy in LQTS patients. However, an ICD may be considered in those patients who are deemed to be at very high risk, especially those with a contraindication to beta-blocker therapy.

Whenever ICD therapy is chosen, thoughtful programming (in particular to prevent inappropriate shocks) is pertinent and usually requires a VF-only zone, with a cutoff rate greater than 220-240 bpm.

\section{LCSD}

This procedure is often effective in reducing the probability for arrhythmic events in high-risk patients, including those who are intolerant of or refractory to beta-blockers alone. ${ }^{21}$ 


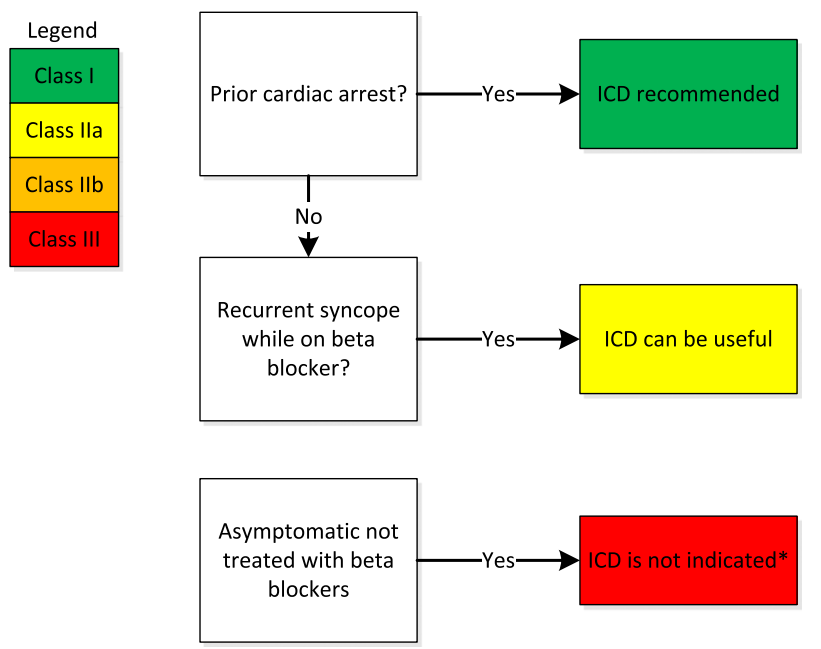

*Except under special circumstances, ICD implantation is not indicated in asymptomatic patients who have not been tried on beta-blocker therapy

Figure 1. Consensus recommendations for ICDs in patients diagnosed with long QT syndrome.

\section{Brugada Syndrome (BrS)}

Expert Consensus Recommendations on BrS Diagnosis

1. BrS is diagnosed in patients with ST-segment elevation with type I morphology $\geq 2 \mathrm{~mm}$ in $\geq 1$ lead among the right precordial leads $\mathrm{V}_{1}, \mathrm{~V}_{2}$ positioned in the $2 \mathrm{nd}$, 3rd, or 4th intercostal space occurring either spontaneously or after provocative drug test with intravenous administration of Class I antiarrhythmic drugs.

2. BrS is diagnosed in patients with type 2 or type 3 ST-segment elevation in $\geq 1$ lead among the right precordial leads $V_{1}, V_{2}$ positioned in the $2 \mathrm{nd}$, 3rd, or 4 th intercostal space when a provocative drug test with intravenous administration of Class I antiarrhythmic drugs induces a type I ECG morphology.

Expert Consensus Recommendations on BrS Therapeutic Interventions

Class I 1. The following lifestyle changes are recommended in all patients with diagnosis of BrS:

a. Avoidance of drugs that may induce or aggravate ST-segment elevation in right precordial leads (e.g., Brugadadrugs.org)

b. Avoidance of excessive alcohol intake

c. Immediate treatment of fever with antipyretic drugs.

2. ICD implantation is recommended in patients with a diagnosis of BrS who:

a. Are survivors of a cardiac arrest and/or

b. Have documented spontaneous sustained VT with or without syncope.

Class 3. ICD implantation can be useful in patients with a IIa spontaneous diagnostic type I ECG who have a history of syncope judged to be likely caused by ventricular arrhythmias.

4. Quinidine can be useful in patients with a diagnosis of BrS and history of arrhythmic storms defined as more than two episodes of VT/VF in 24 hours.

5. Quinidine can be useful in patients with a diagnosis of BrS who:

a. Qualify for an ICD but present a contraindication to the ICD or refuse it and/or

b. Have a history of documented supraventricular arrhythmias that require treatment.

6. Isoproterenol infusion can be useful in suppressing arrhythmic storms in BrS patients.

Class IIb

Class

III

\section{Epidemiology}

No precise data are available on the epidemiology of BrS However, its prevalence is much higher in Asian and Southeast Asian countries, especially Thailand, The Philippines, and Japan, reaching $0.5-1$ per $1000 .^{22} \mathrm{BrS}$ is $8-10$ times more prevalent in men than in women. ${ }^{22}$

\section{Genetic basis}

Inheritance of BrS occurs via an autosomal dominant mode of transmission. Twelve responsible genes have been reported so far. ${ }^{23}$ In all 12 genotypes, either a decrease in the inward sodium or calcium current or an increase in one of the outward potassium currents has been shown to be associated with the BrS phenotype.

\section{Clinical manifestations}

Symptoms associated with BrS include VF or aborted SCD (more often at night than during the day), syncope, nocturnal agonal respiration, palpitations, and chest discomfort. These symptoms often occur during rest or sleep, during a febrile state, or with vagotonic conditions, but rarely during exercise.

\section{Diagnosis}

BrS is definitively diagnosed when a type I ST-segment elevation is observed either spontaneously or after intravenous administration of a sodium channel blocking agent (ajmaline, flecainide, pilsicainde, or procainamide) in at least one right precordial lead $\left(\mathrm{V}_{1}\right.$ and $\left.\mathrm{V}_{2}\right)$, ${ }^{24}$ which are placed in a standard or a superior position (up to the 2nd intercostal space). ${ }^{25,26}$ 


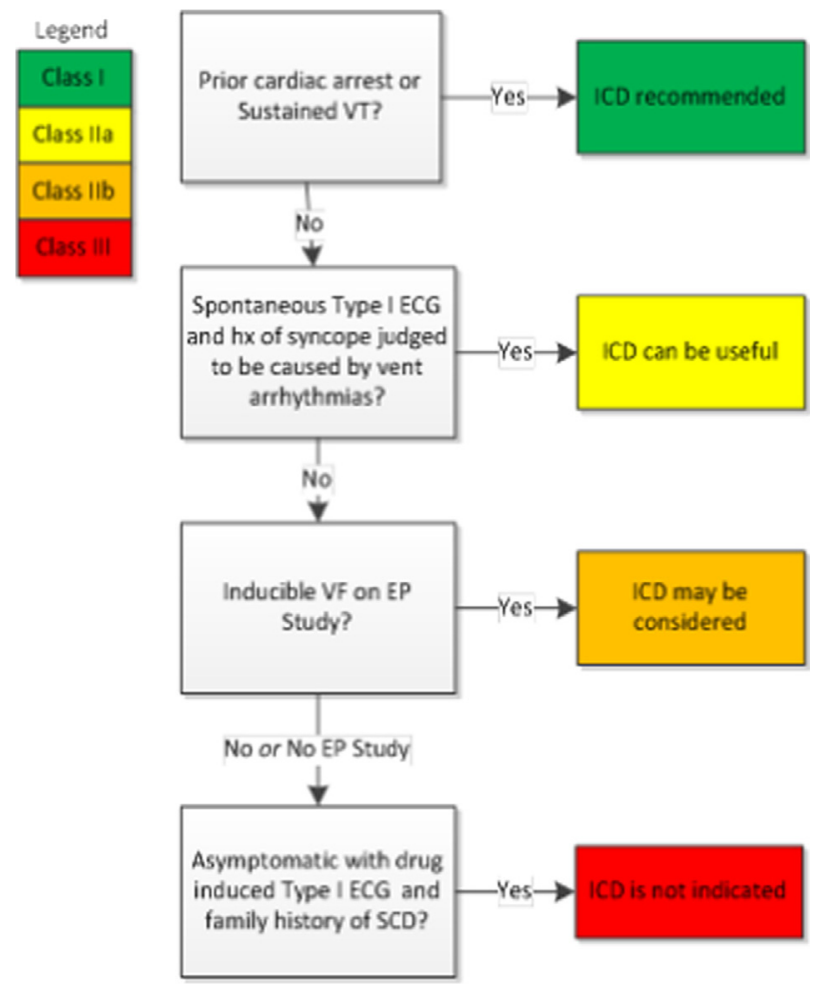

Figure 2. Consensus recommendations for ICDs in patients diagnosed with Brugada syndrome.

\section{Prognosis and risk stratification}

Since the first reporting, the reported annual rate of events has decreased. ${ }^{27-34}$

Several clinical variables have been demonstrated to predict a worse outcome in patients with BrS. The high risk of recurrence of cardiac arrest is seen among patients who have survived a first VF. These patients should be protected with an ICD, irrespective of the presence of other risk factors. ${ }^{22}$

Most studies have concurrently agreed on the evidence that the presence of syncopal episodes in patients with a spontaneous type I ECG at baseline (without conditions known to unmask the signature sign, i.e., drugs and fever) have high risk of cardiac arrhythmic events at follow-up. ${ }^{27-36}$

Among other risk stratification indicators, the presence of fragmented $\mathrm{QRS}^{27,37}$ and an effective refractory period below $200 \mathrm{~ms}^{27,38}$ have been recently proposed. Male sex has consistently been shown to be associated with more arrhythmic events. $^{39}$

Although large registries agree that electrophysiological study (EPS) inducibility is greatest among BrS patients with previous sudden death or syncope, ${ }^{31,32}$ there is no consensus on the value of the EPS in predicting outcome.

\section{Therapeutic options and recommendations for BrS patients}

\section{ICD (Figure 2)}

The only proven effective therapeutic strategy for the prevention of SCD in BrS patients is the ICD. It is important to remark that ICDs are not free from several disadvantages, especially in the group of patients who are active young individuals who will require multiple device replacements during their lifetime. Asymptomatic BrS patients do not qualify for an ICD as their risk for life-threatening events is very low. ${ }^{23}$
Pharmacological treatment in BrS

Isoproterenol (which increases the L-type calcium current) has proved to be useful for the treatment of electrical storm in $\mathrm{BrS},{ }^{40}$ but controlled data on its therapeutic role are not available.

Quinidine, a Class Ia antiarrhythmic drug with transient outward potassium current and rapid delayed rectifier current blocker effects, has been shown to prevent the induction of VF and suppress spontaneous ventricular arrhythmias in a clinical setting.

\section{Radiofrequency catheter ablation in BrS}

After the demonstration that VF events were triggered by ventricular ectopy of similar morphology, radiofrequency ablation of ventricular ectopy has been postulated as a therapeutic approach in BrS patients. Few anecdotal cases in high-risk BrS implanted with an ICD have shown no short-term recurrence of VF, syncope, or SCD. ${ }^{41-44}$ Nademanee et $\mathrm{al}^{45}$ have presented the first series showing that electrical epicardial substrate ablation in the right ventricular outflow tract can prevent VF inducibility in a high-risk population.

\section{Catecholaminergic Polymorphic Ventricular Tachycardia (CPVT)}

\section{Expert Consensus Recommendations on CPVT Diagnosis}

1. CPVT is diagnosed in the presence of a structurally normal heart, normal ECG, and unexplained exercise or catecholamine-induced bidirectional VT or polymorphic ventricular premature beats (VPBs) or VT in an individual younger than 40 years.

2. CPVT is diagnosed in patients (index case or family member) who have a pathogenic mutation.

3. CPVT is diagnosed in family members of a CPVT index case with a normal heart who manifest exercise-induced premature ventricular contractions or bidirectional/ polymorphic VT.

4. CPVT can be diagnosed in the presence of a structurally normal heart and coronary arteries, normal ECG, and unexplained exercise or catecholamine-induced bidirectional VT or polymorphic VPBs or VT in an individual older than 40 years.

\section{Expert Consensus Recommendations on CPVT Therapeutic} Interventions

Class I 1. The following lifestyle changes are recommended in all patients with a diagnosis of CPVT:

a. Limit/avoid competitive sports

b. Limit/avoid strenuous exercise

c. Limit exposure to stressful environments.

2. Beta-blockers are recommended in all symptomatic patients with a diagnosis of CPVT.

3. ICD implantation is recommended in patients with a diagnosis of CPVT who experience cardiac arrest, recurrent syncope or polymorphic/bidirectional VT despite optimal medical management, and/or LCSD.

Class 4. Flecainide can be a useful addition to beta-blockers

IIa in patients with a diagnosis of CPVT who experience recurrent syncope or polymorphic/bidirectional VT while on beta-blockers. 
5. Beta-blockers can be useful in carriers of a pathogenic CPVT mutation without clinical manifestations of CPVT (concealed mutationpositive patients).

Class IIb

6. LCSD may be considered in patients with a diagnosis of CPVT who experience recurrent syncope or polymorphic/bidirectional VT/several appropriate ICD shocks while on beta-blockers and in patients who are intolerant or with contraindication to betablockers.

Class 7. ICD as a stand-alone therapy is not indicated in an III asymptomatic patient with a diagnosis of CPVT.

8. Programmed electrical stimulation is not indicated in CPVT patients.

\section{Introduction}

CPVT is a rare arrhythmogenic disorder characterized by adrenergic-induced bidirectional and polymorphic VT. ${ }^{46,47}$

\section{Epidemiology}

The prevalence of the disease could be as high as 0.1:1000. However, the number is a rough estimate and is not derived from a systematic assessment in the population.

\section{Genetic variants}

Two types of CPVT have been identified: an autosomal dominant form, resulting from mutations in the gene encoding for the cardiac ryanodine receptor $(R y R 2)^{48,49}$ known as CPVT1; and a less common autosomal recessive form, resulting from mutations in the gene for cardiac calsequestrin $(C A S Q 2)^{50,51}$ known as CPVT2. Altogether mutations in $R y R 2^{52}$ and CASQ2 are found in only $60 \%$ of the CPVT patients, ${ }^{1}$ suggesting that other genes may be involved in CPVT. In addition, mutations in KCNJ2 (also causing ATS [LQTS7]), Ank2, TRDN, and CALM1) have been associated with CPVT. ${ }^{53-57}$

\section{Clinical manifestations}

The first clinical episode often manifests in the first or second decade of life and is usually prompted by physical activity or emotional stress. ${ }^{47,58,59}$ When the fainting episode is associated with seizure-like activity, it may be attributed to a neurologic diagnosis, thus causing delay in the diagnosis of CPVT. A family history of exercise-related syncope, seizure, or sudden death is reported in $30 \%$ of the patients and may help directing diagnosis toward CPVT.

\section{Diagnosis}

CPVT patients present a normal resting ECG occasionally with a lower than normal heart rate. ${ }^{47,60}$ When patients start exercising ventricular ectopy develops, increasing in complexity as the heart rate increases. Indeed, initially monomorphic VPBs appear and they may be followed by polymorphic VPBs and bidirectional or polymorphic VT.

\section{Risk stratification}

There are not many indicators of risk of adverse outcome in CPVT. The occurrence of cardiac arrest before diagnosis, but not the occurrence of syncope, is associated with a higher risk of arrhythmic episodes at follow-up. ${ }^{60}$ Similarly, diagnosis in childhood is a predictor of adverse outcome. After diagnosis, the lack of beta-blocker therapy and the use of beta-blockers other than nadolol are independent predictors for arrhythmic events. ${ }^{60}$ Also, the persistence of complex ectopy in exercise tests is a marker for worse outcome. $^{60}$

\section{Management}

\section{Beta-blockers}

The first-line therapeutic option for patients with CPVT is betablockers without intrinsic sympathomimetic activity combined with exercise restriction.

Nadolol being a long-acting drug is preferred for prophylactic therapy and has been found to be clinically effective. The dosage used is usually high $(1-2 \mathrm{mg} / \mathrm{kg})$, with the necessity of a faultless compliance to the therapy. The annual rate of arrhythmic events on beta-blockers ranges between $11 \%$ per year and 3\% per year $(27$ \% over 8 years). ${ }^{60}$ Larger groups of CPVT probands are needed to address the issue of beta-blocker efficacy in CPVT. As nadolol is not available in several countries, it may be suggested that other nonselective beta-blockers are equally effective (i.e., propranolol). Holter recordings and exercise tests should be repeated periodically to assure that the degree of sinus tachycardia that precedes the onset of arrhythmias is known so that in daily life it can be avoided as much as possible. Moreover, to prevent noncompliance-related SCD, it is crucial to alert the patients of the importance of adherence to therapy to preempt life-threatening events.

\section{$I C D$}

An ICD should be considered in CPVT patients who do not respond to an optimal medical management and when LCSD is not possible. All efforts should be made to ensure that patients with an ICD also have an optimal medical treatment. ${ }^{61,62}$ In patients who have experienced an aborted cardiac arrest before the initiation of therapy, beta-blockers or beta-blockers and flecainide should be started and ICD implanted.

Implantation of an ICD is a technical challenge in pediatric patients and problems such as inappropriate shocks, proarrhythmic effects of the ICD, and the need for a lifetime protection requiring multiple reinterventions should be addressed when the decision is taken. Painful shocks by ICD can increase the sympathetic tone and trigger further arrhythmias, leading to a malignant cycle of ICD shocks and even death. Because of this, the ICD should be programmed with long delays before shock delivery and high cutoff rates.

\section{Verapamil}

Verapamil has been shown to be beneficial in some CPVT patients by reducing the ventricular arrhythmia burden on top of beta-blocker therapy during a short-term follow-up period, ${ }^{63,64}$ though its long-term effect remains controversial.

\section{Flecainide}

Flecainide reduces significantly the ventricular arrhythmia burden in a limited number of CPVT patients. ${ }^{65,66}$ A larger study is required to fully elucidate the effect of the drug, but flecainide should now be regarded as the first addition to beta-blockers when control of arrhythmias seems incomplete. 
LCSD

Small series have been published reporting significant results of LCSD on arrhythmic events. ${ }^{67-73}$ Although the short-term results seem encouraging, more data with a long-term follow-up are needed.

\section{Catheter ablation}

Catheter ablation of the bidirectional VPBs that trigger VF may become an adjunctive therapy in patients with refractory CPVT. However, the published experience is very limited and is therefore not discussed in the recommendation. ${ }^{74}$

\section{Evaluation of family members}

Family screening (siblings and parents) by clinical evaluation and genetic testing (when a mutation has been detected) is mandatory to identify undiagnosed patients and asymptomatic carriers who are at risk of arrhythmic events and should be treated. It is suggested that genetically positive family members should receive beta-blockers even after a negative exercise test. $^{60,75}$

\section{Short QT Syndrome (SQTS)}

Expert Consensus Recommendations on SQTS Diagnosis

1. SQTS is diagnosed in the presence of a QTc $\leq 330 \mathrm{~ms}$.

2. SQTS can be diagnosed in the presence of a QTc $<360 \mathrm{~ms}$ and one or more of the following: a pathogenic mutation, family history of SQTS, family history of sudden death at age $\leq 40$ years, and survival of a VT/VF episode in the absence of heart disease.

Expert Consensus Recommendations on SQTS Therapeutic Interventions

Class I 1. ICD implantation is recommended in symptomatic patients with a diagnosis of SQTS who:

a. Are survivors of a cardiac arrest and/or

b. Have documented spontaneous sustained VT with or without syncope.

Class 2. ICD implantation may be considered in

IIb asymptomatic patients with a diagnosis of SQTS and a family history of SCD.

3. Quinidine may be considered in asymptomatic patients with a diagnosis of SQTS and a family history of SCD.

4. Sotalol may be considered in asymptomatic patients with a diagnosis of SQTS and a family history of SCD.

\section{Epidemiology and genetic bases}

One of the rarer cardiac channelopathies is the SQTS. Gussak et $\mathrm{al}^{76}$ were the first to suggest an association with atrial fibrillation and VF (i.e., SCD). With more case reports halfway through the first decade of this century, this association became clearer, ${ }^{77-79}$ but more than 10 years after the first description, the number of patients reported is small, underlining the fact that the disease entity is indeed rare. ${ }^{80}$ Until now, DNA variants in 3 potassium channel genes-KCNH2, KCNQ1, and KCNJ2-have been described to associate with SQTS ${ }^{78,79,81}$; interestingly, mutations in these three genes are also linked with three variants of LQTS: $L Q T 1, L Q T 2$, and $L Q T 7$, respectively.

\section{Clinical diagnosis}

The diagnosis of SQTS is still a matter of debate. A major point of discussion in the definition of diagnostic criteria is represented by the cutoff value at the lower end of the QTC that should be used to diagnose the disease. The QTC should be calculated avoiding tachycardia and bradycardia to prevent the use of Bazett's formula at rates at which its correction is not linear and may lead to the underestimation or overestimation of QTc values.

This group has reached a consensus that a cutoff value of $\leq 330$ ms should be used for the diagnosis.

\section{Risk stratification and treatment}

Therapeutic management using ICDs is undisputed in SQTS patients who have experienced sustained VT/VF episodes. ${ }^{80}$ Appropriate programming of the ICD is needed to prevent inappropriate ICD shocks from T-wave oversensing due to tall T waves. Quinidine seems to be an effective alternative due to the QTprolonging action. Other drugs, including Class III drugs, such as sotalol, are not effective in prolonging the QTc in SQT1 patients, ${ }^{82}$ but may be effective in other subtypes.

The optimal strategy for the primary prevention of cardiac arrest in SQTS is not clear, given the lack of independent risk factors for cardiac arrest.

There are certainly no data to support the implantation of an ICD in asymptomatic patients with SQTS. An ICD might be considered in SQTS patients with a strong family history of SCD and evidence for abbreviated QTc in at least some of the victims.

\section{Early Repolarization (ER)}

Expert Consensus Recommendations on ER Diagnosis

1. ER syndrome is diagnosed in the presence of J-point elevation $\geq 1 \mathrm{~mm}$ in $\geq 2$ contiguous inferior and/or lateral leads of a standard 12-lead ECG in a patient resuscitated from otherwise unexplained VF/polymorphic VT.

2. ER syndrome can be diagnosed in a SCD victim with a negative autopsy and medical chart review, with a previous ECG demonstrating J-point elevation $\geq 1 \mathrm{~mm}$ in $\geq 2$ contiguous inferior and/or lateral leads of a standard 12lead ECG.

3. ER pattern can be diagnosed in the presence of J-point elevation $\geq 1 \mathrm{~mm}$ in $\geq 2$ contiguous inferior and/or lateral leads of a standard 12-lead ECG.

Expert Consensus Recommendations on ER Therapeutic Interventions

Class I 1. ICD implantation is recommended in patients with a diagnosis of ER syndrome who have survived a cardiac arrest.

Class 2. Isoproterenol infusion can be useful in suppressing IIa electrical storms in patients with a diagnosis of ER syndrome. 
3. Quinidine in addition to an ICD can be useful for secondary prevention of VF in patients with a diagnosis of ER syndrome.

Class 4. ICD implantation may be considered in symptomatic IIb family members of ER syndrome patients with a history of syncope in the presence of ST-segment elevation $>1 \mathrm{~mm}$ in two or more inferior or lateral leads.

5. ICD implantation may be considered in asymptomatic individuals who demonstrate a highrisk ER ECG pattern (high J-wave amplitude, horizontal/descending ST-segment) in the presence of a strong family history of juvenile unexplained sudden death with or without a pathogenic mutation.

Class 6. ICD implantation is not recommended in asymptoIII matic patients with an isolated ER ECG pattern.

\section{Definition and epidemiology}

ER is a common ECG pattern characterized by J-point and ST-segment elevation in two or more contiguous leads. The presence of an ER pattern in the precordial leads has been considered a benign phenomenon, but recently its presence in the inferior and/or lateral leads has been associated with idiopathic ventricular fibrillation (IVF) in case-control studies (ER syndrome). ${ }^{83-88}$

The ER ECG pattern ( $>1 \mathrm{~mm}$ ) in the inferior/lateral leads occurs in $1 \%-13 \%$ of the general population and in $15 \%-70 \%$ of the IVF cases. ${ }^{83-91}$ In the pediatric age group, it is even more prevalent. Male sex is strongly associated with the ER ECG pattern, since more than $70 \%$ of the subjects with ER are men. The ER pattern is more common in young physically active individuals, athletes, and African-Americans. ${ }^{92}$ There is an increased prevalence of ER reported in Southeast Asians. ${ }^{89}$

\section{Clinical diagnosis}

Patients with the ER pattern on the 12-lead ECG who have been resuscitated from an ECG-documented episode of IVF and/or polymorphic VT are those diagnosed with ER syndrome. Similarly, SCD victims with a negative autopsy with an archived ECG showing the ER pattern are also diagnosed with ER syndrome when evidence of other diagnoses have been excluded.

At this stage of our understanding of ER, there is an unusual dilemma in which the ECG pattern is highly prevalent, the inheritance is not clearly monogenic in most cases, and the genetic substrate is not clearly defined. For this reason, we have chosen not to label family members with the ER pattern as ER syndrome patients, pending a better understanding of their risk. High-risk features including extent of family history of SCD, arrhythmic syncope, and amplitude and morphology of the ER pattern may lead to consideration of a prophylactic ICD in conjunction with review by an expert center with a focus on inherited arrhythmias. Asymptomatic individuals with the ER pattern on ECG with a mutation considered pathogenic for ER as well as family members of a patient diagnosed with ER syndrome who present with a diagnostic ECG may be affected by the disease.

\section{Genetic variants}

Familial ER has been reported to have an autosomal dominant inheritance pattern with incomplete penetrance. Two independent population-based studies have also suggested some degree of inheritance of the ER patterns in the general population, ${ }^{93,94}$ but the familial inheritance of malignant ER patterns has not been clearly demonstrated. ${ }^{83}$

\section{Clinical manifestations}

Life-threatening arrhythmias are often the first and unexpected manifestation of ER syndrome. The majority of population-based studies have shown that subjects with ER in the inferior leads are at a higher risk of all-cause mortality, cardiac mortality, and especially unexpected sudden death, ${ }^{89-91,95}$ though some exceptions have been reported. ${ }^{96}$

\section{Risk stratification}

The magnitude of the J-point elevation may have prognostic significance. Either slurred or notched J-point elevation $\geq 0.2 \mathrm{mV}$ is relatively rare in the general population but appears to be associated with an increased risk. ${ }^{91}$ A horizontal or descending STsegment elevation following J-point elevation is associated with a worse outcome in the general population. ${ }^{97}$ This observation has been very helpful in distinguishing IVF patients from matched controls and is a key aid in clinical decision making. ${ }^{98}$

\section{Management}

The clinical implications of the observation of an ER pattern in the ECG of an asymptomatic subject are not clear. The presence of ER is associated with three times the risk of developing VF, but the overall risk is still negligible, considering the rarity of VF in the general population. .8,99

Electrical storm is relatively common after ICD implantation in patients with ER syndrome. ${ }^{100,101}$ Case series evidence supports the acute use of isoproterenol for the suppression of recurrent VF and quinidine for long-term suppression. ${ }^{100,101}$ Isoproterenol is typically initiated at $1.0 \mu \mathrm{g} / \mathrm{min}$, targeting a $20 \%$ increase in heart rate or an absolute heart rate $>90 \mathrm{bpm}$, titrated to hemodynamic response and suppression of recurrent ventricular arrhythmia.

\section{Screening of family members}

No recommendations can be given to screen the families of individuals with an asymptomatic ER pattern.

\section{Progressive Cardiac Conduction Disease (PCCD)}

\section{Expert Consensus Recommendations on PCCD Diagnosis}

1. PCCD is diagnosed in the presence of unexplained progressive conduction abnormalities in young ( $<50$ years) individuals with structurally normal hearts in the absence of skeletal myopathies, especially if there is a family history of PCCD.

Expert Consensus Recommendations on PCCD Therapeutic Interventions

Class I 1. Pacemaker implantation is recommended in patients with a diagnosis of PCCD and the presence of:

a. Intermittent or permanent third-degree or high-grade atrioventricular (AV) block or 
b. Symptomatic Mobitz I or II second-degree AV block.

\section{Class 2. Pacemaker implantation can be useful in patients \\ IIa with a diagnosis of PCCD and the presence of bifascicular block with or without first-degree AV block.}

3. ICD implantation can be useful in adult patients diagnosed with PCCD with a mutation in the Lamin $\mathrm{A} / \mathrm{C}$ gene with left ventricular dysfunction and/or nonsustained VT.

\section{Introduction}

PCCD is a heterogeneous disorder of unclear etiology, which can be serious and potentially life-threatening. Its underlying mechanism can be either functional or structural or there can be overlap between these two mechanisms. ${ }^{102}$ The most frequent form of PCCD is a degenerative form called Lenegre-Lev disease. The mechanism of PCCD with structural abnormality is considered as a primary degenerative disease or an exaggerated aging process, with sclerosis principally affecting the conduction tissue. ${ }^{103}$ Aging itself is suggested to play a critical role in PCCD, meaning that at every age, conduction abnormalities are more outspoken than expected based on age alone.

Both familial PCCD with a structurally normal heart (hereby defined as "isolated PCCD") and familial PCCD associated with dilated cardiomyopathy will be discussed.

\section{Genetic variants}

The discovery of gene mutations that are causally involved in inherited PCCD is relatively recent. ${ }^{102}$ Common PCCD-associated genes (defined as genes with causative mutation in more than 5\% of the affected individuals ${ }^{1}$ ) are SCN5A and TRPM4 for PCCD occurring in the structurally intact heart ${ }^{104}$ and LMNA for PCCD associated with heart failure. ${ }^{1}$

\section{PCCD and structurally normal heart}

Mutations in the SCN5A gene cause the majority of familial PCCD and often cause a combined phenotype with BrS. ${ }^{103}$ Subtle structural abnormalities, mainly fibrosis, are present in SCN5A mutation-positive subjects. Recently, mutations in the transient receptor potential channel, subfamily $\mathrm{M}$ (elastatine), member 4 (TRPM4) $\mathrm{Ca}^{2+}$-activated channel gene were reported in patients with PCCD ${ }^{105}$ and are estimated to account for a significant portion of inherited forms of right bundle branch block (25\%) or AV block $(10 \%)^{1}$

\section{PCCD and structurally abnormal heart}

When PCCD is accompanied by the presence of concomitant congenital heart disease, mutations in early cardiac transcription factor genes, such as $N k \times 2.5$ or GATA4, are more likely. Mutations in $N k \times 2.5$ or TBX5, genes involved in the regulation of heart development, are associated with structural congenital heart defects, such as septal defects. ${ }^{103}$

PCCD may also precede the development of dilated cardiomyopathy. Mutations in the LMNA gene encoding Lamin $\mathrm{A} / \mathrm{C}$ were found to be causally involved in Emery-Dreifus muscular dystrophy as well as in families with dilated cardiomyopathies and severe PCCD without skeletal muscle involvement. ${ }^{102,103,106}$

\section{Clinical manifestations}

PCCD can be seen by a prolonged P-wave duration, PR interval, and QRS widening with axis deviation on the surface ECG, which may progress over time as an age-dependent penetrance. In isolated forms of PCCD, there are typically no extracardiac manifestations. In nonisolated forms of PCCD, congenital heart disease, cardiomyopathy, or extracardiac manifestations are present. Phenotypic expression of mutations may vary from individual to individual and has, among others, an age-dependent onset. ${ }^{1}$

In patients with mutations in the LMNA gene and PCCD, the AV node and specialized conduction system are progressively replaced by fibrofatty tissue and patients are at risk for premature SCD. ${ }^{106,107}$ In addition to conduction abnormalities, most adult patients with LMNA mutations have AV conduction disturbances and atrial and ventricular arrhythmias. ${ }^{108}$ Heart failure is a common phenotypic feature in families with cardiac manifestations of LMNA disease. ${ }^{109,110}$ The occurrence of tachyarrhythmia and sudden death is expected to be more frequent in PCCD patients that carry loss-of-function $S C N 5 A$ mutations, a disease entity comparable with SCN5A-associated BrS. ${ }^{102}$

\section{Diagnosis}

The diagnosis of PCCD in an index patient is based on clinical data including history, family history, and 12-lead ECG. The potential presence of congenital heart disease and/or cardiomyopathy must be investigated by 2-D echocardiography or other imaging modalities, such as cardiac magnetic resonance imaging (MRI). Early-onset PCCD in the absence of structural heart disease should prompt consideration of PCCD genetic testing, particularly if there is a positive family history of conduction abnormalities, pacemaker implants, or sudden death. ${ }^{1}$

(Targeted) genetic testing may be considered as part of the diagnostic evaluation for patients with either isolated PCCD or PCCD with concomitant structural heart disease, especially when there is documentation of a positive family history of PCCD. ${ }^{1}$

\section{Risk stratification}

Screening for underlying cardiovascular manifestations with a resting 12-lead ECG, Holter, or 2-D echocardiogram is recommended, independent of symptom status. Patients with firstdegree AV block in association with bifascicular block and symptomatic advanced AV block have a substantial incidence of sudden death. In the presence of permanent or transient third-degree AV block, syncope is associated with an increased incidence of sudden death regardless of EPS results. ${ }^{111}$ Based on this evidence in patients with PCCD diagnosis, pacemaker implant may be indicated even in individuals with bifascicular block and first-degree AV block, thus representing an exception to the recommendation set by international guidelines for patients who have this phenotype in all the other clinical conditions.

Patients with LMNA mutations may experience malignant arrhythmias and SCD despite pacemaker implantation. ${ }^{106}$ ICD therapy is therefore warranted at an early stage; a risk stratification scheme has recently been proposed. ${ }^{112}$

\section{Management}

Once cardiac involvement occurs, particularly with muscular dystrophies, the clinician should maintain a low threshold for 
investigating symptoms or ECG findings to determine the need for EPS, pacemaker, or ICD implantation.

Asymptomatic family members who are positive for the family's PCCD-associated mutation should be prospectively followed for the early development of PCCD-related symptoms, deterioration of cardiac conduction, and beginning signs and symptoms of heart failure. In addition, medications with conduction-slowing properties should be restricted and fever, an aggravating trigger in individuals with SCN5A mutations, should be preemptively treated. ${ }^{1}$

\section{Screening of family members}

Cascade family screening is useful in families with mutationpositive PCCD. When a clinical diagnosis of PCCD is established in an index case, a careful clinical investigation of first-degree family members is necessary. Genotyping of family relatives is done after mutation identification in the index cases and may be useful to exclude the presence or development of PCCD.

\section{Unexplained Cardiac Arrest: Idiopathic VF}

Expert Consensus Recommendations on IVF Diagnosis

1. IVF is diagnosed in a resuscitated cardiac arrest victim, preferably with documentation of VF, in whom known cardiac, respiratory, metabolic, and toxicological etiologies have been excluded through clinical evaluation.

\section{Expert Consensus Recommendations on IVF Evaluation}

Class 1. Genetic testing in IVF can be useful when there is a

IIa suspicion of a specific genetic disease following clinical evaluation of the IVF patient and/or family members.

Class 2. Genetic screening of a large panel of genes in IVF

III patients in whom there is no suspicion of an inherited arrhythmogenic disease after clinical evaluation should not be performed.

Expert Consensus Recommendations on IVF Therapeutic Interventions

Class I 1. ICD implantation is recommended in patients with a diagnosis of IVF.

Class 2. Antiarrhythmic therapy with quinidine,

IIb programmed electrical stimulation guided or empirical, may be considered in patients with a diagnosis of IVF in conjunction with ICD implantation or when ICD implantation is contraindicated or refused.

3. Ablation of Purkinje potentials may be considered in patients with a diagnosis of IVF presenting with uniform morphology premature ventricular contractions in conjunction with ICD implantation or when ICD implantation is contraindicated or refused.

4. If a first-degree relative of an IVF victim presents with unexplained syncope and no identifiable phenotype following thorough investigation, then after careful counseling an ICD implant may be considered.

Expert Consensus Recommendations on IVF Evaluation of Family Members

Class I 1. Evaluation of first-degree relatives of all IVF victims with resting ECG, exercise stress testing, and echocardiography is recommended. Assessment of first-degree relatives with history of palpitations, arrhythmias, or syncope should be prioritized.

2. Follow-up clinical assessment is indicated in young family members of IVF victims who may manifest symptoms and/or signs of the disease at an older age and in all family members whenever additional sudden unexplained death syndrome (SUDS) or sudden unexplained death in infancy (SUDI) events occur.

Class 3. Evaluation of first-degree relatives of IVF victims IIa with Holter and signal-averaged ECGs, cardiac MRI, and provocative testing with Class Ic antiarrhythmic drugs can be useful.

Class 4. Evaluation of first-degree relatives of IVF victims IIb with epinephrine infusion may be considered.

\section{Definition}

When individuals survive a cardiac arrest, we are able to investigate and treat them for the underlying cause. The term "idiopathic ventricular fibrillation" (IVF) is used when the cardiac arrest remains unexplained despite this investigation. In 1992, the hypothesis was advanced that concealed inherited forms of arrhythmogenic disorders could underlie IVF. ${ }^{113}$

\section{Diagnosis}

IVF is diagnosed by the exclusion through clinical evaluation of known cardiac, respiratory, metabolic, and toxicological etiologies that may lead to cardiac arrest. Ideally, VF should be documented.

\section{Management}

In IVF, as there is by definition no evidence for pathogenesis, management is empirical and most patients are advised to undergo an ICD implant. Unfortunately, the natural history of IVF is poorly defined and recurrence of arrhythmic events among IVF patients is not consistent among different studies. ${ }^{114-116}$

\section{Screening of family members}

Experience of investigating blood relatives of IVF survivors is limited. A noninvasive diagnostic protocol similar to that utilized in SUDS families may be employed (see Section 9). As with families of SUDS victims, it is reasonable that relatives of IVF survivors who are obligate carriers or have ominous symptoms such as cardiac syncope should be prioritized for evaluation. In families with IVF, young family members may require periodic reassessment even if the initial assessment is normal as young patients may only 
become cognizant of symptoms at an older age and certain diseases have age-related penetrance. Repeated evaluations should occur if family members become symptomatic or additional suspicious sudden deaths are identified in the family.

\section{Unexplained Sudden Cardiac Death: Sudden Unexplained Death Syndrome (SUDS) and Sudden Unexplained Death in Infancy (SUDI)}

\section{Expert Consensus Recommendations on SUDS Diagnosis}

1. It is recommended that an unexplained sudden death occurring in an individual older than 1 year of age is known as "sudden unexplained death syndrome" (SUDS).

2. It is recommended that a SUDS death with negative pathological and toxicological assessment is termed "sudden arrhythmic death syndrome" (SADS).

\section{Expert Consensus Recommendations on SUDS Evaluation}

Class I 1. It is recommended that personal/family history and circumstances of the sudden death are collected for all SUDS victims.

2. It is recommended that all sudden death victims diagnosed with SUDS undergo expert cardiac pathology to rule out the presence of microscopic indicators of structural heart disease.

3. Collection of blood and/or suitable tissue for molecular autopsy/postmortem genetic testing is recommended in all SUDS victims.

Class 4. An arrhythmia syndrome-focused molecular Ila autopsy/postmortem genetic testing can be useful for all SUDS victims.

Expert Consensus Recommendations on SUDS Therapeutic Interventions

Class I 1. Genetic screening of the first-degree relatives of a SUDS victim is recommended whenever a pathogenic mutation in a gene associated with an increased risk of sudden death is identified by molecular autopsy in the SUDS victim.

2. Evaluation of first-degree blood relatives of all SUDS victims with resting ECG with high right ventricular leads, exercise stress testing, and echocardiography is recommended. Assessment of obligate carriers and relatives with a history of palpitations, arrhythmias, or syncope should be prioritized.

3. Follow-up clinical assessment is indicated in young family members of SUDS victims who may manifest symptoms and/or sign of the disease at an older age and in all family members whenever additional SUDS or SUDI events occur.

Class 4. Evaluation of first-degree relatives of SUDS victims

IIa with ambulatory and signal-averaged ECGs, cardiac MRI, and provocative testing with Class Ic antiarrhythmic drugs can be useful.
Class 5. Evaluation of first-degree relatives of SUDS victims IIb with epinephrine infusion may be considered.

1. It is recommended that unexplained sudden death occurring in an individual younger than 1 year of age with negative pathological and toxicological assessment is termed "sudden unexplained death in infancy" (SUDI).

Expert Consensus Recommendations on SUDI Evaluation

Class I 1. It is recommended that personal/family history and circumstances of the sudden death are collected for all SUDI victims.

2. Collection of blood and/or suitable tissue for molecular autopsy is recommended in all SUDI victims.

Class 3. An arrhythmia syndrome-focused molecular Ila autopsy/postmortem genetic testing can be useful for all SUDI victims.

Class 4. Sudden death victims diagnosed with SUDI at IIb autopsy may be considered for assessment by an expert cardiac pathologist to rule out the presence of microscopic indicators of structural heart disease.

Expert Consensus Recommendations on SUDI Therapeutic Interventions

Class I 1. Genetic screening of the first-degree relatives of a SUDI victim is recommended whenever a pathogenic mutation in a gene associated with increased risk of sudden death is identified by molecular autopsy in the SUDI victim. Obligate mutation carriers should be prioritized.

Class 2. Evaluation of first-degree relatives of SUDI victims

IIa with a family history of inherited heart disease or other SUDS or SUDI deaths with resting ECG and exercise stress testing and additional tests as indicated can be useful. Assessment of first-degree relatives with the history of arrhythmias or syncope should be prioritized.

3. Follow-up clinical assessment can be useful in young family members of SUDI victims with a family history of inherited heart disease or other SUDS or SUDI death who may manifest symptoms and/or signs of the disease at an older age and in all family members whenever additional SUDS or SUDI events occur.

Class 4. Evaluation of first-degree relatives of SUDI victims

IIb with resting ECG and exercise stress testing may be considered. 


\section{Definitions}

An unexplained SCD is a pathological diagnosis of exclusion that covers a number of possible etiologies. A commonly used term is "sudden arrhythmic death syndrome" (SADS) that describes an SCD where an autopsy and toxicology have been undertaken, noncardiac etiologies excluded, and the heart found to be morphologically normal. ${ }^{117,118}$ Another similar descriptor "sudden adult death syndrome" 119 has been termed to describe nonpediatric cases. In Southeast Asia, cases of young male sudden deaths have been attributed to "sudden unexpected or unexplained death syndrome" (SUDS) as well as "sudden unexpected nocturnal death syndrome" (SUNDS). These have, however, been directly related to $\mathrm{BrS}$ as an etiology, have been used interchangeably, and do not necessarily imply a thorough pathological evaluation. ${ }^{120}$ The terms "sudden infant death syndrome" (SIDS) and "sudden unexpected death in infancy" (SUDI) are used in cases younger than 1 year when the cause of death remains unexplained, although SIDS implies a more stringent circumstantial and forensic investigation. These are discussed further below. ${ }^{121}$

\section{Epidemiology}

The incidence of unexplained SCD among the general population aged 4-64 years has been estimated to be up to $1.34 / 100,000$ per annum, ${ }^{118}$ with $4.1 \%$ of the SCD cases in the 16-64 age group being unexplained. ${ }^{119}$ A recent Irish study reported an incidence of unexplained SCD of $0.76 / 100,000$ year in subjects aged $14-35$ years, accounting for $27 \%$ of the total incidence of SCD. ${ }^{122}$

The incidence of unexplained sudden death below 1 year of age (SIDS and SUDI) is well defined and exceeds the incidence of SCD in young adults or in children older than 1 year by an order of magnitude. A recent national study from Ireland revealed a sudden death rate of $1.4 / 100,000$ among children aged $1-4$ years compared to 59/100,000 among children younger than 1 year. ${ }^{123}$ Campaigns to avoid modifiable risk factors (predominantly avoiding the prone sleeping position) have resulted in significant declines in SIDS rates around the world. However, these have plateaued and the current rate of SIDS in the United States is 53/ $100,000 .^{124}$

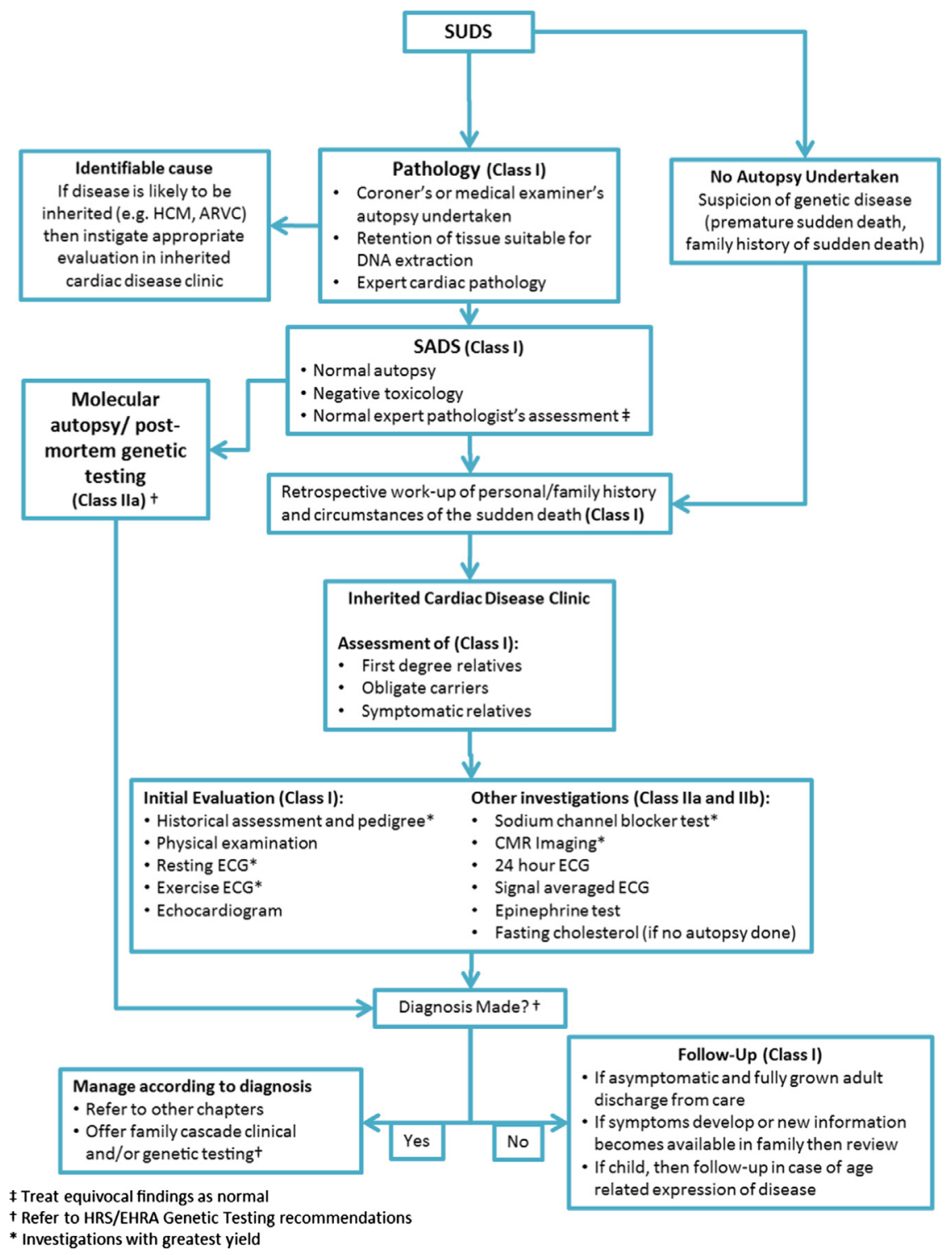

Figure 3. Algorithm to describe the investigative strategy for the identification of inherited heart disease in families that have suffered a SUDS event. 


\section{Diagnosis}

The diagnosis of an unexplained SCD ideally relies on an autopsy, and toxicological studies are undertaken to exclude noncardiac etiologies. Further pathological evaluation of the heart is then necessary with detailed histopathological examination to exclude clear causes for SCD. ${ }^{125}$ This may identify structural cardiac genetic disease such as hypertrophic cardiomyopathy that would indicate the need for familial evaluation and the retention of tissue suitable for DNA extraction and targeted genetic testing. If the death remains unexplained, then additional investigations may prove helpful (see Figure 3).

\section{Screening of family members}

When first-degree relatives of victims of SADS or premature unexplained sudden death undergo cardiac assessment, up to half of families reveal cardiac genetic diseases such as inherited arrhythmia syndromes or subtle forms of cardiomyopathy. ${ }^{117,126-}$ 128 If an autopsy has not been undertaken, then additional etiologies diagnosed in families include cardiomyopathies in general and familial hypercholesterolemia. ${ }^{126,127}$ The strategy for evaluation is often staged with less invasive investigations first and then more invasive tests if a diagnosis is not made, and it is described in Figure 3.

The investigation of family members of cases of SUDI deaths often occurs on an ad hoc basis, yet there are little data on its yield. Molecular autopsy identifies a lower burden of ion channel disease in SIDS compared to SUDS, and there is a greater likelihood of sporadic genetic disease as a cause of sudden death in infancy. It is therefore likely that the yield of clinical evaluation of first-degree relatives will be significantly lower than in SUDS. Nonetheless, if there is a positive molecular autopsy result, a family history of other cases of SUDI, SUDS, or premature unexplained sudden death or of inherited heart disease, then the yield is likely to be greater and familial evaluation more worthwhile.

\section{Inherited Arrhythmia Clinics}

\section{Expert Consensus Recommendations on Inherited Arrhythmia} Clinics

Class 3. Patients (probands) and first-degree relatives with a

I diagnosed or suspected inherited cardiovascular disease as a potential cause of SCD (SUDS/SUDI) should be evaluated in a dedicated clinic with appropriately trained staff

The evaluation and treatment of families suspected of having inherited arrhythmias requires a multidisciplinary team and approach. The presentation is often that of a proband or family member who has experienced a life-threatening arrhythmia, sudden cardiac arrest, or SCD. In the usual circumstances, there are profound and far-reaching medical and psychosocial implications of both presentation of the inherited arrhythmia and genetic testing on patients and families. ${ }^{1,2}$

Recent evidence suggests that a structured inherited arrhythmia (or inherited cardiovascular disease) clinic improves the likelihood of making a diagnosis in suspected cases of inherited arrhythmias and SCD. ${ }^{126,128-132}$ The promise of an appropriately resourced, structured clinic is that of a comprehensive evaluation of patients and families, more efficient use of diagnostic testing and therapy and ready access to a broad range of medical, genetics, and psychosocial expertise in managing families afflicted by inherited arrhythmias. An inherited cardiovascular disease clinic is an invaluable resource to patients and families not only at the time of the initial evaluation but also in an ongoing fashion as medical, genetic, and social questions relevant to the inherited heart disease arise.

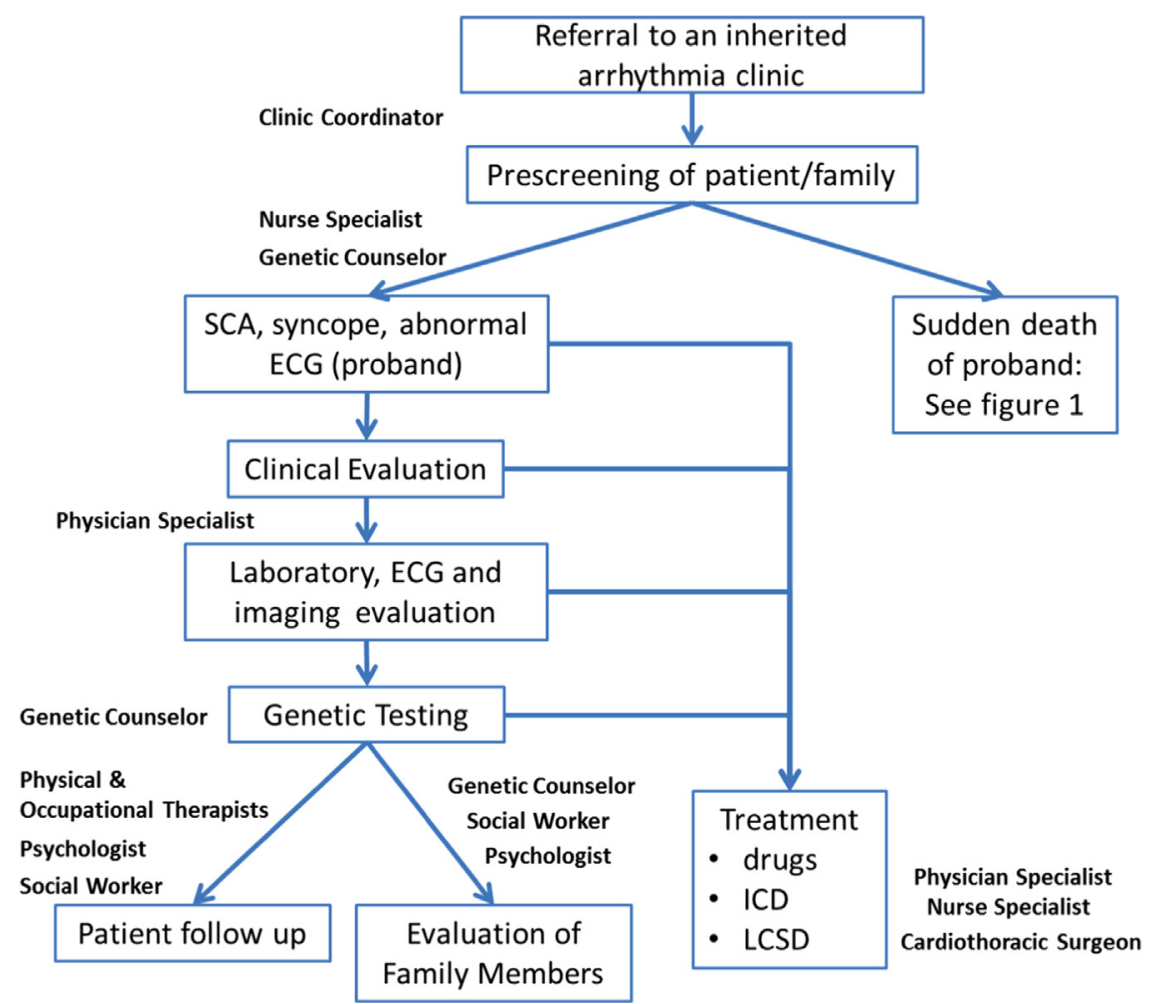

Figure 4. Workflow and personnel in the evaluation of patients and families with inherited arrhythmias. 
Table A1

Writing group author disclosure table

\begin{tabular}{|c|c|c|c|c|c|c|c|}
\hline Writing group & Employment & Consultant/ advisory board & Speakers' bureau/ honoraria & Research grant & Fellowship support & $\begin{array}{l}\text { Board Mbs/ } \\
\text { stock } \\
\text { options/ } \\
\text { partner }\end{array}$ & Others \\
\hline $\begin{array}{l}\text { Nico Blom, } \\
\text { MD, PhD }\end{array}$ & $\begin{array}{l}\text { Academical Medical Center, } \\
\text { Amsterdam, Leiden University } \\
\text { Medical Center, Leiden, } \\
\text { Netherlands }\end{array}$ & None & None & None & None & None & None \\
\hline $\begin{array}{l}\text { Elijah R. Behr, } \\
\text { MA, MBBS, } \\
\text { MD, FRCP }\end{array}$ & $\begin{array}{l}\text { Cardiovascular Sciences Research } \\
\text { Centre, St. Georges University of } \\
\text { London, London, UNITED } \\
\text { KINGDOM }\end{array}$ & None & None & Biotronik & $\begin{array}{l}\text { British Heart Foundation } \\
\text { (f) Boston Scientific-shared } \\
\text { with colleague (f) St. Jude } \\
\text { Medical-shared with colleague } \\
\text { (f) Cardiac Risk in the Young (f) }\end{array}$ & None & $\begin{array}{l}\text { EU-FP7 research project } \\
\text { (f) St. Jude Medical- } \\
\text { consumables for } \\
\text { research (b) British } \\
\text { Heart Foundation- } \\
\text { Research Grants (f) }\end{array}$ \\
\hline $\begin{array}{l}\text { Charles I. } \\
\text { Berul, MD, } \\
\text { FHRS, CCDS }\end{array}$ & $\begin{array}{l}\text { Children's National Medical } \\
\text { Center, Washington, DC, USA }\end{array}$ & $\begin{array}{l}\text { Johnson and Johnson (c) Pierre-Fabre } \\
\text { Pharm (DSMB) (c) }\end{array}$ & None & None & None & None & None \\
\hline $\begin{array}{l}\text { Josep Brugada, } \\
\text { MD, PhD }\end{array}$ & $\begin{array}{l}\text { Thorax Institute, Hospital Clinic, } \\
\text { University of Barcelona, SPAIN }\end{array}$ & Sorin (b) & None & None & None & None & None \\
\hline $\begin{array}{l}\text { Chern-En } \\
\text { Chiang, MD, } \\
\text { PhD }\end{array}$ & $\begin{array}{l}\text { Taipei Veteran's General Hospital } \\
\text { and National Yang Ming } \\
\text { University, Taipei, TAIWAN }\end{array}$ & $\begin{array}{l}\text { Astrazeneca (b); Bayer (b); Boehringer } \\
\text { Ingelheim (b); Daichi-Sankyo (b); } \\
\text { Novartis (b) }\end{array}$ & $\begin{array}{l}\text { Astrazeneca (b); Bayer (b); Boehringer } \\
\text { Ingelheim (b); Daichi-Sankyo (b); } \\
\text { Merck Sharp \& Dohme (b);Novartis (b); } \\
\text { Pfizer (b); Sanofi (b); Roche (b); Servier } \\
\text { (b);Tanabe (b);Takeda (b) }\end{array}$ & None & None & None & None \\
\hline $\begin{array}{l}\text { Yongkeun } \\
\text { Cho, MD, } \\
\text { PhD }\end{array}$ & $\begin{array}{l}\text { Kyungpook National University } \\
\text { Hospital, Taegu, SOUTH KOREA }\end{array}$ & None & None & None & None & None & None \\
\hline $\begin{array}{l}\text { Minoru Horie, } \\
\text { MD, PhD }\end{array}$ & $\begin{array}{l}\text { Shiga University of Medical } \\
\text { Sciences, Department of } \\
\text { Cardiology, Otsu, JAPAN }\end{array}$ & $\begin{array}{l}\text { Daiichi-sankyo (b) Sanofi-Aventis } \\
\text { (b) Boelinger Japan (b) Takeda Pharma } \\
\text { (b) }\end{array}$ & None & None & None & None & None \\
\hline $\begin{array}{l}\text { Heikki } \\
\text { Huikuri, MD }\end{array}$ & $\begin{array}{l}\text { Oulu University Central Hospital, } \\
\text { Division of Cardiology Medicine, } \\
\text { Oulu, FINLAND }\end{array}$ & $\begin{array}{l}\text { Sanofi Winthrop (b) Bohringer } \\
\text { Ingelheim (b) Bayer (b) Merck (b) }\end{array}$ & None & $\begin{array}{l}\text { Daiichi Sankyo } \\
\text { Pharma Dev. (d) }\end{array}$ & None & None & None \\
\hline $\begin{array}{l}\text { Prince } \\
\quad \text { Kannnan- } \\
\text { keril, MD, } \\
\text { HRS }\end{array}$ & $\begin{array}{l}\text { Vanderbilt Children's Hospital, } \\
\text { Division of Pediatric Cardiology, } \\
\text { Nashville, Tennessee }\end{array}$ & None & None & $\mathrm{NIH}(\mathrm{f})$ & None & None & None \\
\hline $\begin{array}{l}\text { Andrew D. } \\
\text { Krahn, MD, } \\
\text { FHRS }\end{array}$ & $\begin{array}{l}\text { University of Western Ontario, } \\
\text { University Hospital, London, } \\
\text { CANADA }\end{array}$ & Medtronic (b) & None & $\begin{array}{l}\text { Medtronic (f) St } \\
\text { Jude Medical } \\
\text { (f) Boston } \\
\text { Scientific (f) }\end{array}$ & $\begin{array}{l}\text { Medtronic (d) St Jude Medical } \\
\text { (c) }\end{array}$ & None & None \\
\hline
\end{tabular}


$\begin{array}{ll}\text { des Maladies Cardiaques } & \text { MSD (b); Boston Scientific (b); } \\ \text { Héréditaires, Paris, France } & \text { Medtronic (b); Biotronik (b); }\end{array}$

Boehringer Ingelheim (b) Genzyme (b)

\begin{tabular}{|c|c|c|c|c|c|c|c|}
\hline $\begin{array}{l}\text { Arthur J. Moss, } \\
\text { MD, HRS }\end{array}$ & $\begin{array}{l}\text { University Rochester Medical } \\
\text { Center, Rochester, NY, USA }\end{array}$ & $\begin{array}{l}\text { Boston Scientific (b); Medtronic (b); } \\
\text { St. Jude (b); Biotronic (b) }\end{array}$ & None & $\begin{array}{l}\text { Boston Scientific } \\
\text { (f) BioReference } \\
\text { Labs (f) NIH (f) }\end{array}$ & None & None & None \\
\hline $\begin{array}{l}\text { Silvia G. Priori, } \\
\text { MD, PhD, } \\
\text { HRS }\end{array}$ & $\begin{array}{l}\text { Maugeri Foundation IRCCS, Pavia, } \\
\text { Italy, Department of Molecular } \\
\text { Medicine, University of Pavia, } \\
\text { Pavia, Italy and New York } \\
\text { University, New York, New York }\end{array}$ & $\begin{array}{l}\text { Medtronic (b); Boston Scientific (b); } \\
\text { Biotronic (b); Transgenomic (b) }\end{array}$ & None & None & None & None & None \\
\hline $\begin{array}{l}\text { Peter J. } \\
\text { Schwartz, } \\
\text { MD, HRS }\end{array}$ & $\begin{array}{l}\text { University of Pavia, Department of } \\
\text { Molecular Medicine, Pavia, ITALY }\end{array}$ & $\begin{array}{l}\text { BioControl Medical Ltd (b) St. Jude } \\
\text { Medical (b) Institut de Recherches } \\
\text { Internationales Servier (b) }\end{array}$ & $\begin{array}{l}\text { Institut de Recherches Internationales } \\
\text { Servier (b) }\end{array}$ & $\begin{array}{l}\text { Institut de } \\
\text { Recherches } \\
\text { Internationales } \\
\text { Servier (b) }\end{array}$ & None & None & None \\
\hline $\begin{array}{l}\text { Wataru } \\
\text { Shimizu, } \\
\text { MD, PhD, } \\
\text { HRS }\end{array}$ & $\begin{array}{l}\text { Nippon Medical School, Tokyo, } \\
\text { Japan }\end{array}$ & $\begin{array}{l}\text { Boelinger Japan (b); Sanofi-Aventis } \\
\text { (b);itsubishi Japan (b); Daiichi-sankyo } \\
\text { (b); Bayer Japan (b);Bristol-Myers } \\
\text { Squibb (b); Medtronic (b); Biotronic } \\
\text { (b) }\end{array}$ & None & None & None & None & None \\
\hline $\begin{array}{l}\text { Gordon } \\
\text { Tomaselli, } \\
\text { MD, FHRS }\end{array}$ & $\begin{array}{l}\text { Johns Hopkins Unviersity, } \\
\text { Baltimore, MD, USA }\end{array}$ & None & None & None & None & $\begin{array}{l}\text { American } \\
\text { Heart } \\
\text { Association } \\
\text { (a) }\end{array}$ & None \\
\hline $\begin{array}{l}\text { Cynthia Tracy, } \\
\text { MD, HRS }\end{array}$ & $\begin{array}{l}\text { George Washington University } \\
\text { Medical Center, Department of } \\
\text { Cardiology, Washington, DC, USA }\end{array}$ & None & None & None & None & None & None \\
\hline $\begin{array}{l}\text { Arthur A } \\
\text { Wilde, MD, } \\
\text { PhD, HRS }\end{array}$ & $\begin{array}{l}\text { University of Amsterdam - } \\
\text { Academic Medical Center, } \\
\text { Amsterdam, NETHERLANDS }\end{array}$ & Sorin (b) & None & None & None & None & None \\
\hline
\end{tabular}

Number Value: $(\mathrm{a})=\$ 0 ;(\mathrm{b})=<\$ 10,000 ;$ (c) $=>\$ 10,000$ to $<\$ 25,000 ;$ (d) $=>\$ 25,000$ to $<\$ 50,000$; (e) $=>\$ 50,000$ to $<\$ 100,000$; (f) $=>\$ 100,000$. 
Peer reviewer disclosure table

\begin{tabular}{|c|c|c|c|c|c|c|c|}
\hline Peer review & Employment & Consultant/ advisory board & $\begin{array}{l}\text { Speakers' } \\
\text { bureau/ } \\
\text { honoraria }\end{array}$ & Research grant & Fellowship support & $\begin{array}{l}\text { Board Mbs/ } \\
\text { stock } \\
\text { options/ } \\
\text { partner }\end{array}$ & Others \\
\hline $\begin{array}{l}\text { Michael Ackerman, } \\
\text { MD, PhD }\end{array}$ & $\begin{array}{l}\text { Mayo Clinic College of Medicine, } \\
\text { Rochester, MN, USA }\end{array}$ & $\begin{array}{l}\text { 1; Biotronik, Boston Scientific Corp., Medtronic Inc., St. Jude } \\
\text { Medical }\end{array}$ & None & 5; National Institutes of Health & None & None & $\begin{array}{l}\text { Royalties-4; } \\
\text { Transgenomic }\end{array}$ \\
\hline $\begin{array}{l}\text { Bernard Belhassen, } \\
\text { MD }\end{array}$ & $\begin{array}{l}\text { Tel Aviv Medical Center, Tel Aviv, } \\
\text { ISRAEL }\end{array}$ & None & None & None & None & None & None \\
\hline $\begin{array}{l}\text { N. A. Mark Estes III, } \\
\text { MD, FHRS }\end{array}$ & $\begin{array}{l}\text { New England Medical Center, } \\
\text { Boston, MA, USA }\end{array}$ & 1; Medtronic Inc. 2; Boston Scientific Corp. & None & 4: Boston Scientific Corp. & $\begin{array}{l}\text { 4; Medtronic Inc., } \\
\text { Boston Scientific } \\
\text { Corp., St. Jude } \\
\text { Medical }\end{array}$ & None & None \\
\hline Diane Fatkin, MD & $\begin{array}{l}\text { Victor Change Cardiac Research } \\
\text { Institute, Darlinghurst, } \\
\text { AUSTRALIA }\end{array}$ & None & None & $\begin{array}{l}\text { 5; NHMRC Senior Research } \\
\text { Fellowship }\end{array}$ & None & None & $\begin{array}{l}\text { Salary- 4; Victor Chang } \\
\text { Cardiac Research } \\
\text { Institute, partial salary } \\
\text { support }\end{array}$ \\
\hline $\begin{array}{l}\text { Jonathan Kalman, } \\
\text { PhD, FHRS }\end{array}$ & $\begin{array}{l}\text { Royal Melbourne Hospital, } \\
\text { Melbourne, AUSTRALIA }\end{array}$ & None & None & 4; Medtronic, Inc. & $\begin{array}{l}\text { 3; St. Jude Medical } \\
\text { 4; Medtronic Inc. }\end{array}$ & None & None \\
\hline $\begin{array}{l}\text { Elizabeth Kaufman, } \\
\text { MD, FHRS }\end{array}$ & $\begin{array}{l}\text { Metrohealth Medical Center, } \\
\text { Cleveland, OH, USA }\end{array}$ & 1; St. Jude Medical & None & 2; Cambridge Heart, Inc. & None & None & None \\
\hline $\begin{array}{l}\text { Paulus Kirchhof, } \\
\text { MD }\end{array}$ & University Hospital Muenster & $\begin{array}{l}\text { 1; 3M Medica, Bayer Healthcare LLC, Bristol Meyers Squibb, } \\
\text { Eli Lilly, Boehringer Ingelheim, Daiichi, Medtronic Inc., } \\
\text { Sanofi Aventis, St. Jude Medical, Merck Parmaceuticals }\end{array}$ & None & $\begin{array}{l}\text { 5; Sanofi Aventis, St. Jude Medical, } \\
\text { 3M Medica, German Ministry of } \\
\text { Education and Research (BMBF) }\end{array}$ & None & None & None \\
\hline $\begin{array}{l}\text { Eric Schulze-Bahr, } \\
\text { MD, PhD }\end{array}$ & $\begin{array}{l}\text { University of Munster, Munster, } \\
\text { GERMANY }\end{array}$ & None & None & None & None & None & None \\
\hline $\begin{array}{l}\text { Christian Wolpert, } \\
\text { MD }\end{array}$ & $\begin{array}{l}\text { University Hospital Mannheim, } \\
\text { Ludwigsburg, GERMANY }\end{array}$ & $\begin{array}{l}\text { 1; Medtronic Inc., St. Jude Medical, Bard Electrophysiology, } \\
\text { Sorin Group }\end{array}$ & None & None & None & None & None \\
\hline Jitendra Vohra, MD & $\begin{array}{l}\text { Royal Melbourne Hospital, } \\
\text { Melbourne, AUSTRALIA }\end{array}$ & None & None & None & None & None & None \\
\hline Marwan Refaat, MD & $\begin{array}{l}\text { Univeristy of California, San } \\
\text { Francisco, CA, USA }\end{array}$ & None & None & None & None & None & None \\
\hline $\begin{array}{l}\text { Susan P. Etheridge, } \\
\text { MD, FHRS }\end{array}$ & $\begin{array}{l}\text { University of Utah, Salt Lake City, } \\
\text { UT, USA }\end{array}$ & None & None & None & None & None & None \\
\hline $\begin{array}{l}\text { Robert M. } \\
\text { Campbell, MD }\end{array}$ & $\begin{array}{l}\text { Sibley Heart Center, Emory } \\
\text { University School of Medicine, } \\
\text { Atlanta, GA, USA }\end{array}$ & None & None & None & None & None & None \\
\hline $\begin{array}{l}\text { Edward T. Martin, } \\
\text { MD }\end{array}$ & $\begin{array}{l}\text { Oklahoma Heart Institute, Tulsa, } \\
\text { OK, USA }\end{array}$ & 1; Lantheus, Siemens, & None & None & None & None & None \\
\hline $\begin{array}{l}\text { Swee Chye Quek, } \\
\text { MD }\end{array}$ & $\begin{array}{l}\text { National Univeristy of Singapore, } \\
\text { SINGAPORE }\end{array}$ & None & None & None & None & None & None \\
\hline
\end{tabular}

Number Value: $0=\$ 0 ; 1=\leq \$ 10,000 ; 2=>\$ 10,001$ to $\leq \$ 25,000 ; 3=>\$ 25,001$ to $\leq \$ 50,000 ; 4=>\$ 50,001$ to $\leq 100,000 ; 5=>\$ 100,001$. 
There are different operational models for inherited arrhythmia clinics; the choice may be determined by the health system or the regulations that exist in a given country. The personnel and workflow in an ideal inherited arrhythmia clinic is illustrated schematically in Figure 4. The key personnel include a clinic coordinator who is responsible for patient intake, collection and collation of medical records, scheduling appointments for patients and family members, and assisting with questions relating to insurance coverage. The physicians are typically a clinical cardiologist/electrophysiologist with expertise in inherited arrhythmias and medical genetics or a medical geneticist with an interest in cardiac arrhythmias partnering with a clinical electrophysiologist. If the inherited arrhythmia clinic is part of a larger program in inherited heart disease, experts in cardiomyopathy will likely be available; otherwise access to such experts is essential.

The increasing complexity and demands of the proper diagnosis and management of patients with inherited cardiovascular disease creates an opportunity for the development of specialized training for clinical electrophysiologists interested in the care of patients with inherited arrhythmias. ${ }^{133}$ Such a specialty track would consolidate aspects of care involving indications and interpretation of genetic test results and pharmacological and device therapy.

The management of patients with inherited arrhythmias includes expert judgment regarding the indications, type, and interpretation of genetic testing. In collaboration with a genetic counselor, patients and families should be properly prepared regarding expectations and outcomes of genetic testing. Arguably the most important part of the testing procedure is reviewing the test results and implications with patient and family, with counselor being prepared to discuss the implications for other family members, the meaning of variants of uncertain significance, mosaicism, and issues related to paternity and consanguinity. The genetic counselor is an essential ${ }^{134}$ and, in some countries, legally mandated provider in this aspect of the care of patients and families with suspected inherited arrhythmias.

The treatment of patients with inherited arrhythmias may vary from medication therapy and lifestyle modification to device implantation to LCSD. Patients may require invasive EPS and treatment with pacemakers or ICDs.

Patients in an inherited arrhythmia clinic may be survivors of sudden cardiac arrest. The management of the recovery of these patients from their index event may require the expertise of psychologists and psychiatrists, and the intervention of physical and occupational therapists. Moreover, the diagnosis of an inherited disease of any kind, particularly one that carries with it the risk of significant morbidity and premature mortality, is often associated with significant emotional distress that at times will require referral of patients and families. ${ }^{135-141}$

A structured inherited arrhythmia (or heart disease) clinic provides the platform for optimized multidisciplinary evaluation and management of patients and families with suspected inherited heart disease. The collective efforts of the core staff and access to a variety of experts in related disciplines will result in improved quality of care, ${ }^{128,131,139,142-147}$ patient satisfaction, ${ }^{138}$ and improvement in the appropriate use of diagnostic testing ${ }^{126,130}$ and therapeutic intervention. The promise of such a clinic structure is lower overall cost and improvement in patient outcomes.

\section{Appendix A}

See Tables A1 and A2.

\section{References}

1 Ackerman MJ, et al. HRS/EHRA expert consensus statement on the state of genetic testing for the channelopathies and cardiomyopathies this document was developed as a partnership between the Heart Rhythm Society (HRS) and the European Heart Rhythm Association (EHRA). Heart Rhythm 2011;8: 1308-39.

2 Zipes DP, et al. ACC/AHA/ESC 2006 Guidelines for Management of Patients With Ventricular Arrhythmias and the Prevention of Sudden Cardiac Death: a report of the American College of Cardiology/American Heart Association Task Force and the European Society of Cardiology Committee for Practice Guidelines (writing committee to develop Guidelines for Management of Patients With Ventricular Arrhythmias and the Prevention of Sudden Cardiac Death): developed in collaboration with the European Heart Rhythm Association and the Heart Rhythm Society. Circulation 2006;114:e385-484.

3 Task Force for the Diagnosis and Management of Syncope, et al. Guidelines for the diagnosis and management of syncope (version 2009). Eur Heart J 2009:30:2631-2671.

4 Strickberger SA, et al. AHA/ACCF Scientific Statement on the evaluation of syncope: from the American Heart Association Councils on Clinical Cardiology, Cardiovascular Nursing, Cardiovascular Disease in the Young, and Stroke, and the Quality of Care and Outcomes Research Interdisciplinary Working Group; and the American College of Cardiology Foundation: in collaboration with the Heart Rhythm Society: endorsed by the American Autonomic Society. Circulation 2006;113:316-27.

5 Schwartz PJ, et al. Prevalence of the congenital long-QT syndrome. Circulation 2009;120:1761-7.

6 Moss AJ, et al. ECG T-wave patterns in genetically distinct forms of the hereditary long QT syndrome. Circulation 1995;92:2929-34.

7 Schwartz PJ, Crotti L. QTc behavior during exercise and genetic testing for the long-QT syndrome. Circulation 2011;124:2181-4.

8 Schwartz PJ, et al. Diagnostic criteria for the long QT syndrome: an update. Circulation 1993;88:782-4.

9 Priori SG, et al. Risk stratification in the long-QT syndrome. N Engl J Med 2003;348:1866-74.

10 Goldenberg I, et al. Risk for life-threatening cardiac events in patients with genotype-confirmed long-QT syndrome and normal-range corrected QT intervals. J Am Coll Cardiol 2011;57:51-9.

11 Schwartz PJ, et al. The Jervell and Lange-Nielsen syndrome: natural history, molecular basis, and clinical outcome. Circulation 2006;113:783-90.

12 Splawski I, et al. Ca(V)1.2 calcium channel dysfunction causes a multisystem disorder including arrhythmia and autism. Cell 2004;119:19-31.

13 Goldenberg I, et al. Risk factors for aborted cardiac arrest and sudden cardiac death in children with the congenital long-QT syndrome. Circulation 2008;117:2184-91.

14 Priori SG, et al. Association of long QT syndrome loci and cardiac events among patients treated with beta-blockers. JAMA 2004;292:1341-4.

15 Schwartz PJ, Spazzolini C, Crotti L. All LQT3 patients need an ICD: true or false? Heart Rhythm 2009;6:113-20.

16 Spazzolini C, et al. Clinical implications for patients with long QT syndrome who experience a cardiac event during infancy. J Am Coll Cardiol 2009;54:832-7.

17 Jons C, et al. Risk of fatal arrhythmic events in long QT syndrome patients after syncope. J Am Coll Cardiol 2010;55:783-8.

18 Zareba W, et al. Implantable cardioverter defibrillator in high-risk long QT syndrome patients. J Cardiovasc Electrophysiol 2003;14:337-41.

19 Schwartz PJ, et al. Who are the long-QT syndrome patients who receive an implantable cardioverter-defibrillator and what happens to them? Data from the European Long-QT Syndrome Implantable Cardioverter-Defibrillator (LQTS ICD) Registry Circulation 2010;122:1272-82.

20 Horner JM, et al. Implantable cardioverter defibrillator therapy for congenital long QT syndrome: a single-center experience. Heart Rhythm 2010;7:1616-22.

21 Schwartz PJ, et al. Left cardiac sympathetic denervation in the management of high-risk patients affected by the long-QT syndrome. Circulation 2004;109:1826-33.

22 Antzelevitch $\mathrm{C}$, et al. Brugada syndrome: report of the second consensus conference. Heart Rhythm 2005;2:429-40.

23 Mizusawa Y, Wilde AA. Brugada syndrome. Circ Arrhythm Electrophysiol 2012;5:606-16

24 Sarkozy A, et al. The value of a family history of sudden death in patients with diagnostic type I Brugada ECG pattern. Eur Heart J 2011;32:2153-60.

25 Miyamoto K, et al. Diagnostic and prognostic value of a type 1 Brugada electrocardiogram at higher (third or second) V1 to V2 recording in men with Brugada syndrome. Am J Cardiol 2007;99:53-7.

26 Nagase S, et al. Electroanatomical correlation of repolarization abnormalities in Brugada syndrome: detection of type 1 electrocardiogram in the right ventricular outflow tract. J Am Coll Cardiol 2010;56:2143-5.

27 Priori SG, et al. Risk stratification in Brugada syndrome: results of the PRELUDE (PRogrammed ELectrical stimUlation preDictive valuE) registry. J Am Coll Cardiol 2012;59:37-45.

28 Brugada J, et al. Long-term follow-up of individuals with the electrocardiographic pattern of right bundle-branch block and ST-segment elevation in precordial leads V1 to V3. Circulation 2002;105:73-8.

29 Brugada J, Brugada R, Brugada P. Determinants of sudden cardiac death in individuals with the electrocardiographic pattern of Brugada syndrome and no previous cardiac arrest. Circulation 2003;108:3092-6.

30 Brugada P, Brugada R, Brugada J. Should patients with an asymptomatic Brugada electrocardiogram undergo pharmacological and electrophysiological testing? Circulation 2005;112:279-92 (discussion 279-292).

31 Priori SG, et al. Natural history of Brugada syndrome: insights for risk stratification and management. Circulation 2002;105:1342-7. 
32 Eckardt L, et al. Long-term prognosis of individuals with right precordial ST-segment-elevation Brugada syndrome. Circulation 2005;111:257-63.

33 Brugada P, Brugada J. Right bundle branch block, persistent ST segment elevation and sudden cardiac death: a distinct clinical and electrocardiographic syndrome. A multicenter report. J Am Coll Cardiol 1992;20:1391-6.

34 Kamakura S, et al. Long-term prognosis of probands with Brugada-pattern ST-elevation in leads V1-V3. Circ Arrhythm Electrophysiol 2009;2:495-503.

35 Brugada J, Brugada R, Brugada P. Right bundle-branch block and ST-segment elevation in leads V1 through V3: a marker for sudden death in patients without demonstrable structural heart disease. Circulation 1998;97:457-60.

36 Benito B, et al. Gender differences in clinical manifestations of Brugada syndrome. J Am Coll Cardiol 2008;52:1567-73.

37 Kusano KF, et al. Atrial fibrillation in patients with Brugada syndrome relationships of gene mutation, electrophysiology, and clinical backgrounds. J Am Coll Cardiol 2008;51:1169-75.

38 Makimoto $\mathrm{H}$, et al. Clinical impact of the number of extrastimuli in programmed electrical stimulation in patients with Brugada type 1 electrocardiogram. Heart Rhythm 2012;9:242-8.

39 Gehi AK, et al. Risk stratification of individuals with the Brugada electrocardiogram: a meta-analysis. J Cardiovasc Electrophysiol 2006;17:577-83.

40 Maury P, Hocini M, Haissaguerre M. Electrical storms in Brugada syndrome: review of pharmacologic and ablative therapeutic options. Indian Pacing Electrophysiol J 2005;5:25-34.

41 Haissaguerre $\mathrm{M}$, et al. Mapping and ablation of ventricular fibrillation associated with long-QT and Brugada syndromes. Circulation 2003;108:925-8.

42 Darmon JP, et al. Radiofrequency ablation of ventricular fibrillation and multiple right and left atrial tachycardia in a patient with Brugada syndrome. J Interv Card Electrophysiol 2004;11:205-9.

43 Nakagawa E, et al. Successful radiofrequency catheter ablation for electrical storm of ventricular fibrillation in a patient with Brugada syndrome. Circ J 2008;72:1025-9.

44 Morita $\mathrm{H}$, et al. Epicardial ablation eliminates ventricular arrhythmias in an experimental model of Brugada syndrome. Heart Rhythm 2009;6: 665-71.

45 Nademanee K, et al. Prevention of ventricular fibrillation episodes in Brugada syndrome by catheter ablation over the anterior right ventricular outflow tract epicardium. Circulation 2011:123:1270-9.

46 Coumel P, et al. Catecholamine-induced severe ventricular arrhythmias with Adams-Stokes syndrome in children: report of four cases. Br Heart J 1978;40: $28-37$.

47 Leenhardt A, et al. Catecholaminergic polymorphic ventricular tachycardia in children: a 7-year follow-up of 21 patients. Circulation 1995;91:1512-9.

48 Priori SG, et al. Mutations in the cardiac ryanodine receptor gene (hRyR2) underlie catecholaminergic polymorphic ventricular tachycardia. Circulation 2001;103:196-200.

49 Laitinen PJ, et al. Mutations of the cardiac ryanodine receptor (RyR2) gene in familial polymorphic ventricular tachycardia. Circulation 2001;103:485-90.

50 Lahat $\mathrm{H}$, et al. Autosomal recessive catecholamine- or exercise-induced polymorphic ventricular tachycardia: clinical features and assignment of the disease gene to chromosome 1p13-21. Circulation 2001;103:2822-7.

51 Lahat $\mathrm{H}$, et al. A missense mutation in a highly conserved region of CASQ2 is associated with autosomal recessive catecholamine-induced polymorphic ventricular tachycardia in Bedouin families from Israel. Am J Hum Genet 2001;69:1378-84.

52 Medeiros-Domingo A, et al. The RYR2-encoded ryanodine receptor/calcium release channel in patients diagnosed previously with either catecholaminergic polymorphic ventricular tachycardia or genotype negative, exerciseinduced long QT syndrome: a comprehensive open reading frame mutational analysis. J Am Coll Cardiol 2009;54:2065-74.

53 Vega AL, et al. Protein kinase A-dependent biophysical phenotype for V227FKCNJ2 mutation in catecholaminergic polymorphic ventricular tachycardia. Circ Arrhythm Electrophysiol 2009;2:540-7.

54 Bhuiyan ZA, et al. A novel early onset lethal form of catecholaminergic polymorphic ventricular tachycardia maps to chromosome 7p14-p22. J Cardiovasc Electrophysiol 2007;18:1060-6.

55 Mohler PJ, et al. A cardiac arrhythmia syndrome caused by loss of ankyrin-B function. Proc Natl Acad Sci U S A 2004;101:9137-42.

56 Roux-Buisson $\mathrm{N}$, et al. Absence of triadin, a protein of the calcium release complex, is responsible for cardiac arrhythmia with sudden death in human. Hum Mol Genet 2012;21:2759-67.

57 Nyegaard M, et al. Mutations in calmodulin cause ventricular tachycardia and sudden cardiac death. Am J Hum Genet 2012;91:703-12.

58 Sumitomo N, et al. Catecholaminergic polymorphic ventricular tachycardia: electrocardiographic characteristics and optimal therapeutic strategies to prevent sudden death. Heart 2003;89:66-70.

59 Priori SG, et al. Clinical and molecular characterization of patients with catecholaminergic polymorphic ventricular tachycardia. Circulation 2002;106: 69-74.

60 Hayashi $\mathrm{M}$, et al. Incidence and risk factors of arrhythmic events in catecholaminergic polymorphic ventricular tachycardia. Circulation 2009;119: 2426-34.

61 van der Werf C, Zwinderman AH, Wilde AA. Therapeutic approach for patients with catecholaminergic polymorphic ventricular tachycardia: state of the art and future developments. Europace 2012;14:175-83.

62 Venetucci L, et al. Inherited calcium channelopathies in the pathophysiology of arrhythmias. Nat Rev Cardiol 2012;9:561-75.
63 Rosso R, et al. Calcium channel blockers and beta-blockers versus betablockers alone for preventing exercise-induced arrhythmias in catecholaminergic polymorphic ventricular tachycardia. Heart Rhythm 2007;4:1149-54.

64 Swan H, et al. Calcium channel antagonism reduces exercise-induced ventricular arrhythmias in catecholaminergic polymorphic ventricular tachycardia patients with RyR2 mutations. J Cardiovasc Electrophysiol 2005;16: $162-6$.

65 van der Werf C, et al. Flecainide therapy reduces exercise-induced ventricular arrhythmias in patients with catecholaminergic polymorphic ventricular tachycardia. J Am Coll Cardiol 2011;57:2244-54.

66 Watanabe $\mathrm{H}$, et al. Flecainide prevents catecholaminergic polymorphic ventricular tachycardia in mice and humans. Nat Med 2009;15:380-3.

67 Wilde AA, et al. Left cardiac sympathetic denervation for catecholaminergic polymorphic ventricular tachycardia. N Engl J Med 2008;358:2024-9.

68 Atallah J, et al. Video-assisted thoracoscopic cardiac denervation: a potential novel therapeutic option for children with intractable ventricular arrhythmias. Ann Thorac Surg 2008;86:1620-5.

69 Collura CA, et al. Left cardiac sympathetic denervation for the treatment of long QT syndrome and catecholaminergic polymorphic ventricular tachycardia using video-assisted thoracic surgery. Heart Rhythm 2009;6:752-9.

70 Gopinathannair R, et al. Delayed maximal response to left cardiac sympathectomy for catecholaminergic polymorphic ventricular tachycardia. Europace 2010;12:1035-9.

71 Chen SY, Cucchiaro G, Bushman G. The role of thoracic epidural blockade in predicting responsiveness to left sympathetic denervation in patients with catecholaminergic polymorphic ventricular tachycardia. J Cardiothorac Vasc Anesth 2011:25:844-6.

72 Odero A, et al. Left cardiac sympathetic denervation for the prevention of lifethreatening arrhythmias: the surgical supraclavicular approach to cervicothoracic sympathectomy. Heart Rhythm 2010;7:1161-5.

73 Coleman MA, et al. Videoscopic left cardiac sympathetic denervation for patients with recurrent ventricular fibrillation/malignant ventricular arrhythmia syndromes besides congenital long-QT syndrome. Circ Arrhythm Electrophysiol 2012;5:782-8.

74 Kaneshiro T, et al. Successful catheter ablation of bidirectional ventricular premature contractions triggering ventricular fibrillation in catecholaminergic polymorphic ventricular tachycardia with RyR2 mutation. Circ Arrhythm Electrophysiol 2012;5:e14-7.

75 van der Werf C, et al. Familial evaluation in catecholaminergic polymorphic ventricular tachycardia: disease penetrance and expression in cardiac ryanodine receptor mutation-carrying relatives. Circ Arrhythm Electrophysio 2012;5:748-56.

76 Gussak I, et al. Idiopathic short QT interval: a new clinical syndrome? Cardiology 2000;94:99-102.

77 Gaita F, et al. Short QT syndrome: a familial cause of sudden death. Circulation 2003;108:965-70.

78 Brugada R, et al. Sudden death associated with short-QT syndrome linked to mutations in HERG. Circulation 2004;109:30-5.

79 Bellocq C, et al. Mutation in the KCNQ1 gene leading to the short QT-interval syndrome. Circulation 2004;109:2394-7.

80 Giustetto C, et al. Long-term follow-up of patients with short QT syndrome. J Am Coll Cardiol 2011;58:587-95.

81 Priori SG, et al. A novel form of short QT syndrome (SQT3) is caused by a mutation in the KCNJ2 gene. Circ Res 2005:96:800-7.

82 Gaita F, et al. Short QT syndrome: pharmacological treatment. J Am Coll Cardiol 2004;43:1494-9.

83 Haissaguerre M, et al. Sudden cardiac arrest associated with early repolarization. N Engl J Med 2008;358:2016-23.

84 Rosso R, et al. J-point elevation in survivors of primary ventricular fibrillation and matched control subjects: incidence and clinical significance. J Am Coll Cardiol 2008:52:1231-8.

85 Abe A, et al. Circadian variation of late potentials in idiopathic ventricular fibrillation associated with J waves: insights into alternative pathophysiology and risk stratification. Heart Rhythm 2010;7:675-82.

86 Nam GB, et al. Mode of onset of ventricular fibrillation in patients with early repolarization pattern vs. Brugada syndrome. Eur Heart J 2010;31:330-9.

87 Derval N, et al. Prevalence and characteristics of early repolarization in the CASPER registry: cardiac arrest survivors with preserved ejection fraction registry. J Am Coll Cardiol 2011;58:722-8.

88 Rosso R, et al. Risk of sudden death among young individuals with J waves and early repolarization: putting the evidence into perspective. Heart Rhythm 2011;8:923-9.

89 Haruta D, et al. Incidence and prognostic value of early repolarization pattern in the 12-lead electrocardiogram. Circulation 2011;123:2931-7.

90 Sinner MF, et al. Association of early repolarization pattern on ECG with risk of cardiac and all-cause mortality: a population-based prospective cohort study (MONICA/KORA). PLoS Med 2010;7:e1000314.

91 Tikkanen JT, et al. Long-term outcome associated with early repolarization on electrocardiography. N Engl J Med 2009;361:2529-37.

92 Junttila MJ, et al. Inferolateral early repolarization in athletes. J Interv Card Electrophysiol 2011;31:33-8.

93 Noseworthy PA, et al. The early repolarization pattern in the general population: clinical correlates and heritability. J Am Coll Cardiol 2011;57:2284-9.

94 Reinhard W, et al. Heritability of early repolarization: a population-based study. Circ Cardiovasc Genet 2011;4:134-8. 
95 Patel RB, et al. Early repolarization associated with ventricular arrhythmias in patients with chronic coronary artery disease. Circ Arrhythm Electrophysiol 2010;3:489-95.

96 Uberoi A, et al. Early repolarization in an ambulatory clinical population. Circulation 2011;124:2208-14.

97 Tikkanen JT, et al. Early repolarization: electrocardiographic phenotypes associated with favorable long-term outcome. Circulation 2011;123:2666-73.

98 Rosso R, et al. Distinguishing "benign" from "malignant early repolarization": the value of the ST-segment morphology. Heart Rhythm 2012;9:225-9.

$99 \mathrm{Wu} \mathrm{SH}$, et al. Early repolarization pattern and risk for arrhythmia death: meta-analysis. J Am Coll Cardiol 2013;61:645-50.

100 Nam GB, Kim YH, Antzelevitch C. Augmentation of J waves and electrical storms in patients with early repolarization. N Engl J Med 2008:358:2078-9.

101 Haissaguerre M, et al. Characteristics of recurrent ventricular fibrillation associated with inferolateral early repolarization role of drug therapy. J Am Coll Cardiol 2009;53:612-9.

102 Smits JP, Veldkamp MW, Wilde AA. Mechanisms of inherited cardiac conduction disease. Europace 2005;7:122-37.

103 Schott JJ, Charpentier F, Le Marec H. Progressive cardiac conduction disease. In: Gussak I, Antzelevitch C, editors. Electrical Diseases of the Heart. London: Springer-Verlag; 2008. p. 564-76.

104 Stallmeyer B, et al. Mutational spectrum in the $\mathrm{Ca}(2+)$-activated cation channel gene TRPM4 in patients with cardiac conductance disturbances. Hum Mutat 2012;33:109-17.

105 Kruse M, et al. Impaired endocytosis of the ion channel TRPM4 is associated with human progressive familial heart block type I. J Clin Invest 2009; 119:2737-44.

106 Wolf CM, et al. Lamin A/C haploinsufficiency causes dilated cardiomyopathy and apoptosis-triggered cardiac conduction system disease. J Mol Cell Cardio 2008;44:293-303.

107 Wolf CM, Berul CI. Inherited conduction system abnormalities-one group of diseases, many genes. J Cardiovasc Electrophysiol 2006;17:446-55.

108 van Berlo JH, et al. Meta-analysis of clinical characteristics of 299 carriers of LMNA gene mutations: do lamin A/C mutations portend a high risk of sudden death? J Mol Med (Berl) 2005;83:79-83.

109 Taylor MR, et al. Natural history of dilated cardiomyopathy due to lamin A/C gene mutations. J Am Coll Cardiol 2003;41:771-80.

110 Parks SB, et al. Lamin A/C mutation analysis in a cohort of 324 unrelated patients with idiopathic or familial dilated cardiomyopathy. Am Heart J 2008; 156:161-9.

111 Epstein AE, et al. ACC/AHA/HRS 2008 Guidelines for device-based therapy of cardiac rhythm abnormalities. Heart Rhythm 2008;5:e1-62.

112 van Rijsingen IA, et al. Risk factors for malignant ventricular arrhythmias in lamin a/c mutation carriers a European cohort study. J Am Coll Cardiol 2012;59:493-500.

113 Priori SG, et al. Unexplained cardiac arrest: the need for a prospective registry. Eur Heart J 1992;13:1445-6.

114 Crijns HJ, et al. Favourable outcome in idiopathic ventricular fibrillation with treatment aimed at prevention of high sympathetic tone and suppression of inducible arrhythmias. Br Heart J 1995;74:408-12.

115 Remme CA, et al. Diagnosis and long-term follow-up of the Brugada syndrome in patients with idiopathic ventricular fibrillation. Eur Heart J 2001;22:400-9.

116 Knecht S, et al. Long-term follow-up of idiopathic ventricular fibrillation ablation: a multicenter study. J Am Coll Cardiol 2009;54:522-8.

117 Behr E, et al. Cardiological assessment of first-degree relatives in sudden arrhythmic death syndrome. Lancet 2003;362:1457-9.

118 Behr ER, et al. Sudden arrhythmic death syndrome: a national survey of sudden unexplained cardiac death. Heart 2007;93:601-5.

119 Bowker TJ, et al. Sudden, unexpected cardiac or unexplained death in England: a national survey. QJM 2003;96:269-79.

120 Vatta M, et al. Genetic and biophysical basis of sudden unexplained nocturnal death syndrome (SUNDS), a disease allelic to Brugada syndrome. Hum Mo Genet 2002;11:337-45.

121 Krous HF, et al. Sudden infant death syndrome and unclassified sudden infant deaths: a definitional and diagnostic approach. Pediatrics 2004;114:234-8.

122 Margey R, et al. Sudden cardiac death in 14- to 35-year olds in Ireland from 2005 to 2007: a retrospective registry. Europace 2011;13:1411-1418.

123 McGarvey CM, et al. Sudden unexplained death in childhood (1-4 years) in Ireland: an epidemiological profile and comparison with SIDS. Arch Dis Child 2012;97:692-7.
124 Trachtenberg FL, et al. Risk factor changes for sudden infant death syndrome after initiation of Back-to-Sleep campaign. Pediatrics 2012;129:630-8.

125 Basso C, et al. Guidelines for autopsy investigation of sudden cardiac death. Virchows Arch 2008;452:11-8.

126 van der Werf $C$, et al. Diagnostic yield in sudden unexplained death and aborted cardiac arrest in the young: the experience of a tertiary referral center in the Netherlands. Heart Rhythm 2010;7:1383-9.

127 Tan HL, et al. Sudden unexplained death: heritability and diagnostic yield of cardiological and genetic examination in surviving relatives. Circulation 2005; 112:207-13.

128 Behr ER, et al. Sudden arrhythmic death syndrome: familial evaluation identifies inheritable heart disease in the majority of families. Eur Heart J 2008;29:1670-80.

129 Priori SG, Napolitano C. Role of genetic analyses in cardiology. Part I: Mendelian diseases: cardiac channelopathies. Circulation 2006;113:1130-5.

130 Bai R, et al. Yield of genetic screening in inherited cardiac channelopathies: how to prioritize access to genetic testing. Circ Arrhythm Electrophysiol 2009;2:6-15.

131 Hofman N, et al. Active cascade screening in primary inherited arrhythmia syndromes: does it lead to prophylactic treatment? J Am Coll Cardiol 2010;55:2570-6.

132 Nunn LM, Lambiase PD. Genetics and cardiovascular disease-causes and prevention of unexpected sudden adult death: the role of the SADS clinic. Heart 2011;97:1122-7.

133 van Langen IM, et al. Genetic knowledge and counselling skills of Dutch cardiologists: sufficient for the genomics era? Eur Heart J 2003;24:560-6.

134 Ingles J, Yeates L, Semsarian C. The emerging role of the cardiac genetic counselor. Heart Rhythm 2011;8:1958-62.

135 Hendriks KS, et al. Familial disease with a risk of sudden death: a longitudinal study of the psychological consequences of predictive testing for long QT syndrome. Heart Rhythm 2008;5:719-24.

136 Hendriks KS, et al. Can parents adjust to the idea that their child is at risk for a sudden death? Psychological impact of risk for long QT syndrome Am J Med Genet A 2005;138A:107-12.

137 Hendriks KS, et al. High distress in parents whose children undergo predictive testing for long QT syndrome. Community Genet 2005;8:103-13.

138 Christiaans I, et al. Genetic counseling and cardiac care in predictively tested hypertrophic cardiomyopathy mutation carriers: the patients' perspective. Am J Med Genet A 2009;149A:1444-51.

139 Christiaans I, et al. Quality of life and psychological distress in hypertrophic cardiomyopathy mutation carriers: a cross-sectional cohort study. Am J Med Genet A 2009;149A:602-12.

140 Hoedemaekers E, Jaspers JP, Van Tintelen JP. The influence of coping styles and perceived control on emotional distress in persons at risk for a hereditary heart disease. Am J Med Genet A 2007;143A:1997-2005.

141 Hamang A, et al. General anxiety, depression, and physical health in relation to symptoms of heart-focused anxiety-a cross-sectional study among patients living with the risk of serious arrhythmias and sudden cardiac death. Health Qual Life Outcomes 2011;9:100.

142 Christiaans I, et al. Obtaining insurance after DNA diagnostics: a survey among hypertrophic cardiomyopathy mutation carriers. Eur J Hum Genet 2010;18:251-3.

143 van Langen IM, et al. Family and population strategies for screening and counselling of inherited cardiac arrhythmias. Ann Med 2004;36:116-24.

144 Christiaans I, et al. Uptake of genetic counselling and predictive DNA testing in hypertrophic cardiomyopathy. Eur J Hum Genet 2008;16:1201-7.

145 Cohen LL, et al. Challenges of genetic testing in adolescents with cardiac arrhythmia syndromes. J Med Ethics 2012;38:163-7.

146 Caldwell J, et al. The clinical management of relatives of young sudden unexplained death victims; implantable defibrillators are rarely indicated. Heart 2012;98:631-6.

147 Ingles J, et al. Guidelines for genetic testing of inherited cardiac disorders Heart Lung Circ 2011;20:681-7. 